\title{
LA GESTIÓ TÉCNICA DE LA IRRIGACIÓ EN LES HORTES HISTÒRIQUES VALENCIANES. EL SEQUIER, DELS ORÍGENS A LA DESAPARICIÓ (SEGLES XIII-XVII)
}

\author{
THE TECHNICAL MANAGEMENT OF IRRIGATION IN \\ HISTORICAL VALENCIAN IRRIGATED AREAS. THE \\ 'SEQUIER', FROM THE ORIGINS TO THE END, 13TH- \\ 17TH CENTURIES
}

\author{
Ferran Esquilache Martí \\ EnRIC Guinot Rodríguez \\ Universitat de València
}

\begin{abstract}
RESUM
Darrerament s'està parant molta atenció a les institucions de govern del regadiu, però la gestió tècnica de manteniment de la xarxa i el control dels usuaris és una qüestió molt diferent. A les hortes valencianes aquesta funció l'ha acomplert històricament el sequier, un càrrec molt conegut en l'espai rural que ha estat ben estudiat en l'àmbit local, però del qual no existia una visió global per a tot el país. En aquest treball intentarem esbrinar quins són els seus orígens, com va evolucionar en època baix-medieval i moderna, i per què va començar a desaparèixer cap al segle XVII.
\end{abstract}

Paraules clau: Irrigació, hortes, sequier, institucions, acció col.lectiva

\begin{abstract}
Recently, some authors have paid close attention to irrigation management institutions, but technical maintenance management is very different from exercising control over users. In the irrigated region of Valencia, this role has historically been carried out by the "Sequier", a position which is well known in rural areas and one which has been studied thoroughly at a local level, but not globally in the context of the whole country. In this paper we shall try to establish its origins, its evolution in late medieval and modern times and the reasons why it began to disappear toward the seventeenth century.
\end{abstract}

Keywords: Irrigation, 'huertas', 'sequier', institutions, collective action 
En regions com el món Mediterrani, on la irregularitat anual de les pluges és una de les seues característiques climàtiques, la creació d'àmbits de regadiu artificial ha estat una constant al llarg dels segles. De fet, l'arqueologia trau periòdicament a la llum restes materials de canals i basses de diverses èpoques del passat, no sols medievals sinó també de les més antigues etapes musulmanes, romanes i fins i tot ibèriques, de més de 2.000 anys. Però la història del regadiu, lògicament, no es limita a les infraestructures sinó que, per al seu bon funcionament, les diverses societats del passat disposaren de mecanismes collectius d'organització del reg i del repartiment de l'aigua, tant de cara a millorar la seva eficiència com per a intentar evitar, tant com fos possible, els conflictes entre persones i entre col.lectivitats.

Sovint es tendeix a pensar en unes institucions del reg de molt llarga durada, fins i tot mil.lenàries, però la realitat és ben diferent. Justament els canvis esdevinguts en la forma d'organització de les societats del passat han marcat també la gènesi de formes diferents en la gestió dels regadius. Allò més habitual és que les estructures materials (assuts o presses, canals o séquies, basses o embassaments, partidors de diversos tipus, molins, etc.) hagen passat els segles amb escassos canvis físics i materials, deixant de banda reparacions i reconstruccions parcials per destruccions. Només amb l'impacte de la Revolució Industrial i les noves fonts d'energia (vapor i electricitat des de finals del segle XIX) han canviat significativament algunes d'elles. Però front a aquesta "llarga durada" material, les estructures socials d'organització del regadiu han canviat molt més en profunditat amb la successió dels diferents sistemes històrics que s'han succeït a tot el món Mediterrani: el sistema esclavista dels romans, el sistema tribal-tributari de la societat islàmica, el sistema feudal medieval i modern, i finalment el sistema burgés-capitalista dels dos darrers segles d'època contemporània.

En l'actualitat, la forma d'organització d'aquestes institucions és la dels sindicats o comunitats de regants, generada a partir dels canvis legislatius de l'Estat liberal al segle XIX, tal com han estudiat Marc Ferri i Carles Sanchis (FerRI, 2007; FERRI i SANCHIS, 2001). Es tracta d'un model basat en la Junta directiva elegida periòdicament pels membres de la comunitat, i encapçalada per un síndic-president que té capacitats de decisió i direcció de la institució, amb el suport i l'assessorament de la resta de la Junta i de 
diversos empleats assalariats que gestionen els aspectes més tècnics o materials del reg: guardes, regadors, administratius, etc. A fi de comptes, un model estructural similar al d'altres institucions de poder de la societat contemporània, com ara els Ajuntaments (alcalde-president, regidors, empleats o funcionaris tècnics i administratius, etc.).

Probablement, l'exemple més conegut i visible del protagonisme dels síndics-presidents és la composició actual del conegut Tribunal de les Aigües de València, una institució que, diven, tindria uns orígens mil.lenaris i que es reuneix cada dijous a les dotze del matí a la porta dels Apòstols de la Seu de València. Les vuit persones que s'hi seven actualment per a jutjar els plets de reg de l'Horta de València són els síndics-presidents de les vuit séquies o comunitats de regants d'aquesta ciutat (GUINOT i ROMERO, 2007). Però, com dèiem adés, aquestes organitzacions i càrrecs no han existit sempre de la mateixa manera. I, efectivament, quan anem als arxius a cercar la història social $\mathrm{i}$ institucional de les séquies i sistemes de reg valencians, ens trobem amb una diversitat més gran que, a més a més, va anar canviant al llarg dels segles a partir d'època medieval: des de comunes d'hereters molt similars als gremis medievals en la seva organització, a sistemes municipalistes controlats pels consells locals, i sobretot formes col.lectives de gestió no presidencialistes.

Tanmateix, tant en un cas com en l'altre la responsabilitat de la distribució de l'aigua, del manteniment de les infraestructures o del control dels regants -en definitiva, la gestió directa del sistema-va estar en mans d'una persona concreta al marge de les institucions de govern comunals o municipals: el sequier. Aquesta figura ja ha estat estudiada abans per altres autors, que anirem citant al llarg del text, però sempre des d'una perspectiva local, i amb una gran segmentació cronològica. El que volem fer a continuació, doncs, és donar-li un tractament global a nivell de tot el País Valencià, en la mesura que ho permeta la documentació, i també una perspectiva històrica de més llarg abast. En definitiva, volem intentar explicar com i per què va aparèixer aquesta figura a les hortes valencianes ja en època andalusina, quines funcions de gestió tècnica i control de la irrigació concretes tenia assignades, com va evolucionar al llarg dels segles, i finalment, també, intentarem plantejar per què va desaparèixer entre finals del segle XVII i al llarg del segle XVIII.

\section{L'ORGANITZACIÓ INSTITUCIONAL DEL REGADIU}

El 29 de desembre de 1239, poc més d'un any després de la conquesta de la ciutat de València per Jaume l, el rei atorgava un privilegi als seus primers pobladors cristians que venia a sumar-se a tot un ventall de documents 
reials anteriors. Aquests tenien com a objectiu posar en marxa des de diversos vessants la nova societat feudal que s'estava bastint al nou regne, tant institucionalment com administrativa, però també econòmica i en la pràctica diària. Aquest privilegi per als nous colons instal.lats a la ciutat parlava de la cort del justícia, de l'ofici municipal del mostassaf, de la concessió franca del dret de pastura per als seus veïns, i també els hi feia donació de totes les séquies i canals de l'horta, així com de l'aigua que hi corria tant de dia com de nit.' En conseqüència, d'ací es derivaria l'organització i govern institucional del regadiu a l'Horta de València.

Però aquesta concessió de les aigües de reg i de les corresponents séquies per part de la monarquia a la capital del nou regne no fou una excepció, sinó que aquesta mena de donacions, redactades d'una manera o d'una altra, van ser habituals a les dècades centrals del segle XIII per a la gran majoria de poblacions valencianes, des de la Plana de Castelló fins a les muntanyes de la frontera sud del nou regne de València. A les cartes de poblament de localitats amb grans hortes, com ara Borriana o Xàtiva, se'n fa menció, i també va ser habitual als llocs petits que només tenien sistemes irrigats per fonts, tant si eren de jurisdicció reial com senyorial.

Per la seua banda, a les localitats on continuaren existint comunitats rurals de musulmans, perquè no van ser expulsats o desplaçats durant la conquesta cristiana, es degueren mantenir els sistemes tradicionals d'organització del reg en mans de les seves respectives aljames. Lamentablement, no ens han arribat documents que ens informen sobre com funcionava aquesta organització en aquell moment. Per contra, sí en tenim allà on hi hagué un repoblament amb colons cristians, als quals se'ls va donar una nova normativa d'ús que ens ha arribat en algunes ocasions, per això ací només parlarem bàsicament de com funcionaven aquest casos.

\subsection{Un triple sistema organitzatiu del govern del regadiu}

L'organització dels sistemes de reg valencians del segle XIII adoptà una triple forma institucional, tot $\mathrm{i}$ que no eren totalment divergents $\mathrm{i}$ tenien punts en comú entre totes tres models. Així, en primer lloc, es crearen comunes

1 "Donamus et concedimus imperpetuum omnes et singulas cequias civitatis Valencie maiores, mediocres et minores cum aquis et aquarum ductibus excepta cequia qui vocatur Regia, illa scilicet que vadit usque ad Puçolum. Quarum cequiarum aquam et aquarum ductum habeatis semper continue et incessanter die et nocte; ita quod ex eis possitis rigare secundum quod est antiquitus consuetum" (1239, desembre, 29). Arxiu Municipal de València (AMV), Pergamins, n. 3, publicat per CORTÉs (2001), doc. 8. 
autònomes a la ciutat de València i a la ciutat de Xàtiva per concessió reial, constituïdes per aquells que posseïen terres regades per cada séquia major o sistema hidràulic. El segon model fou l'anomenat municipal, això és, que tant la corona com els altres senyors donaren la possessió, gestió i organització dels sistemes hidràulics als nous consells municipals que s'anaren fundant i consolidant durant aquell primer segle. Aquest procés, però, no sempre fou immediat a la colonització, i trobem localitats que no reberen el control i govern del sistema de regadiu fins a les darreries del segle XIII, com ara Castelló de la Plana. Tanmateix, el model municipal fou el que va predominar arreu de les terres valencianes, en veure's facilitat pel fet que la major part dels sistemes hidràulics estaven físicament construïts dins d'un únic terme municipal i/o jurisdiccional; tot i que hi hagués excepcions com l'Horta de Gandia, o la Séquia comuna de l'Ėnova.

Resumint, doncs, podríem dir que el sistema de comunes es va desenvolupar en aquells sistemes de reg d'origen andalusí que regaven en diversos termes municipals $\mathrm{i}$ estaven situats al voltant de les ciutats, com València $\mathrm{i}$ Xàtiva. ${ }^{2}$ Per contra, als sistemes que estaven dins d'un sol terme municipal, o que encara que fos compartit per diverses poblacions no estaven en l'horta d'una ciutat, es va desenvolupar el sistema municipal. ${ }^{3}$

No és ara el moment d'endinsar-se en una anàlisi detallada d'aquests dos models de govern collectiu, puix no és el tema de l'article, però és necessari explicar alguns aspectes bàsics per a entendre la funció i el paper del sequier. En el cas del govern municipal eren els jurats de cada localitat els que regien el sistema hidràulic, prenent decisions sobre els problemes de captació de l'aigua del riu o de la font corresponent, o encarregant i pagant les obres de manteniment i reparació de les infraestructures amb major entitat, com els assuts. Igualment, negociaven amb altres poders locals veïns que compartien el riu, i de vegades el sistema, o bé amb els oficials reials i senyorials que poguessen tenir interessos en el control de l'aigua, com en el cas dels molins. També eren els jurats i el consell municipal els que nomenaven o arrendaven a un especialista, el sequier, la gestió diària

2 Amb tot, cal dir que en la mateixa València també hi havia un control municipal en els sistemes hidràulics de nova construcció, realitzats a partir del segle XIV sobre les marjals (Guck, 2003: 93-101).

3 Per exemple, a l'Horta de Gandia tant la mateixa vila de Gandia com la d'Oliva, i la Font d'en Carròs, que comparteixen el sistema, tenien el seu propi sequier cadascú, i mantenien entre tots l'assut i el tram de séquia comuna (CASTILO, 1997). Per la seua banda, Castelló i Almassora també compartien assut, però no sequier ni govern de la séquia; i en el cas de la séquia comuna de l'Ėnova cada senyoriu tenia el seu propi sequier. A més a més, en aquest darrer cas unes localitats eren de cristians i altres de musulmans. 
del sistema hidràulic durant un temps, i l'arrendament el feien mitjançant subhastes públiques al millor postor. És a dir, que aquell sequier que oferia gestionar la séquia a un preu més barat, que seria pagat mitjançant una derrama econòmica pels veïns que posseïen terres irrigades, era nomenat sequier per un període limitat, normalment d'un o dos anys depenent dels casos, o de cinc en certes ocasions.

El cas de la ciutat de València era un poc diferent, i una mica excepcional, ja que arran del privilegi reial del 1239 es constitüren diverses comunes formades pels propietaris de les terres irrigades (anomenats hereters a la documentació), una per cada sistema hidràulic de l'Horta, a les qual s'afegí Montcada el 1268. I també és excepcional perquè aquestes comunes, autònomes del poder municipal i del reial, han perdurat fins al segle XXI, si bé $a m b$ evidents modificacions internes en l'organització i repartiment de les competències al llarg dels segles. Resumint molt, el model d'època foral, fins al segle XVIII, fou el d'una direcció collectiva, que presentava moltes semblances amb els gremis artesanals coetanis, però també en certa manera amb el funcionament dels consells municipals de govern local.

En les comunes hi havia una Junta directiva formada pels diputats, que eren nomenats per les assemblees anuals o bianuals dels hereters o propietaris de les terres irrigades per cada séquia. Això, evidentment, en el cas de la ciutat de València excloïa a una part considerable dels veritables llauradors, ja que aquests eren emfiteutes en unes terres que eren majoritàriament propietat de cavallers i nobles, de burgesos i notaris, o també $d^{\prime}$ institucions eclesiàstiques com monestirs, etc. A més, cada comuna tenia un síndic $\mathrm{i}$ un clavari, amb funcions específiques de gestió administrativa i de control del sequier, però no de govern. El primer, almenys fins al segle $\mathrm{XVI}$, solia ser un notari, ja que era el que representava legalment a la comuna, tant en plets judicials com en la contractació de préstecs econòmics o davant de les autoritats locals i oficials reials. Pel que fa al clavari, com el seu nom indica, era el tresorer de la comunitat.

Finalment, hi havia els "veedors e conexedors de la céquia", que per exemple a la comuna de Mislata eren sis el 1415 i en la de Favara onze el 1446, un per cada nucli de poblament o partida d'hàbitat dispers. La seva funció era vigilar o supervisar allò que feia el sequier en cadascun dels seus respectius braços o zona d'actuació, acompanyar el síndic en la supervisió de l'escura de la séquia mare, i també aconsellar el sequier als judicis; a canvi, eren francs del pagament del sequiatge mentre durava el seu mandat. En definitiva, doncs, una espècie d'inspectors com els va anomenar Thomas Glick (2003: 84), que sempre eren hereters llauradors, ja que la seua funció de supervisió del sequier i del correcte funcionament del sistema així ho requeria. Aquestes diferències socials en les persones que 
ocupaven els càrrecs ens dóna una bona pista sobre la divisió social al govern de les séquies, probablement més marcada en el cas de les comunes de les séquies que envoltaven les ciutats de València i Xàtiva, que no en la major part dels casos amb un control del regadiu municipal perquè, deixant de banda les viles, a sovint, eren pobles menuts en els quals la gran majoria dels propietaris eren tots llauradors.

Fins ací l'explicació del funcionament dels dos models més habituals de gestió i govern dels sistemes hidràulics, que són els que van acabar consolidant-se al llarg de l'època foral, i dels quals ja va parlar Glick (2003: 67-93). Dos models sensiblement diferents que tenien en comú una gestió i control col.lectiu del regadiu. Però encara va haver-hi un tercer model, com ja hem apuntat, diferent a aquest dos, que va acabar desapareixent $\mathrm{i}$ només va existir en aquell primer segle posterior a la conquesta. En aquest model la corona va mantenir el control directe d'uns pocs sistemes hidràulics mitjançant oficials reials. És el cas, per exemple, de la Reial Séquia de Montcada, a l'horta de València, que finalment fou donada l'any 1268 per Jaume I als propietaris de terres que usaven la seua aigua, com havia fet ja el 1239 amb la resta de séquies. ${ }^{4}$ En el cas de Castelló de la Plana fou la senyoria, en aquell moment en mans del monestir de Sant Victorià de Sobrarbe, qui va donar als seus veïns la gestió de la Séquia Major de Castelló el 1283. I abans de finals de segle va passar el mateix amb la Séquia Reial d'Alzira i amb la Séquia Major de Vila-real, ambdues construïdes ex-novo per iniciativa reial uns anys després de la conquesta. ${ }^{5}$

En aquest darrer cas la figura del batle reial local va cobrar especial rellevància com a supervisor del sequier, que al principi era nomenat també pel rei, igual que en el cas de la Séquia Reial d'Alzira que coneixem un poc millor (Gual Camarena, 1979). En conseqüència, a diferencia dels models comunal i municipal, que eren sistemes de govern col.lectiu malgrat les seues peculiaritats individuals, el model reial presentava un govern individualitzat en mans dels oficials de la corona. Amb tot, com podem veure el batle reial tenia la mateixa funció que tenien el síndic i els veedors de les comunes autònomes, i també la que tenien els jurats dels consells municixiu Municipal d'Alzira (AMA), Llibre de privilegis, vol. 36, f. 51r-53r, publicat per Gual (1979). En el cas de Vila-real no sabem la data de cessió, però hagué de ser després de 1291, quan el rei encara dóna instruccions al batle sobre el sequiatge (ROMÁN, 2000: 247), i abans de 1307, que és quan tenim documentat el primer arrendament pels jurats (ROMÁN, 2000: 105; GARCIA Edo, 1994: 132-134). 
pals: supervisar la gestió del sistema i el treball directe del sequier. Aquest personatge, que només s'ocupava de la gestió, doncs, era el punt en comú de tots tres models, i el que ens interessa ara.

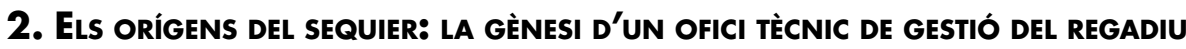

Com acabem de veure, una cosa és la forma institucional que adopta el govern del regadiu, i una altra distinta la gestió directa i funcional del sistema en el dia a dia. Així doncs, independentment del model, reial, municipal o comunal, en tots els sistemes de regadiu era el sequier qui s'ocupava de la distribució de l'aigua entre els regants, de vigilar el compliment de les normes, etc., amb una sèrie d'ajudants que després veurem. Però com va sorgir aquest càrrec $o$ ofici? I quines funcions concretes tenia?

Tot sembla indicar que no es tracta d'una innovació del segle XIII, sinó que el seu origen és andalusí i que fou adoptat pels cristians, o millor dit adaptat a la nova societat feudal. Que la nomenclatura de sequier, o acequiero en castellà, vinga directament de la fonetització a les llengües romàniques del mot àrab sāqiya és un bon argument. I també la freqüent referència en els documents al fet que els sistemes de reg devien funcionar "com en temps de sarraïns". Però és cert que el mot sequier no el tenim documentat abans de les conquesta, i que no està tan clar que es tracte d'una adopció directa d'una institució andalusina. Per tant, anant pas per pas, primer caldrà que ens fixem en l'oficial andalusí que, aparentment, més se li aproxima: el șāhib al-sāqiya.

\subsection{Els antecedents andalusins i catalano-aragonesos}

En al-Àndalus, abans del segle XIII, sabem que havien existit, com a mínim, fins a quatre càrrecs o autoritats locals que intervenien en el govern o en la gestió de l'aigua: el qādi al-miyāh, l'amīn al-mā", el muhtasib i el șăhib al-sāqiya. Els tres primers estan associats quasi sempre a l'entorn urbà, però en sabem ben poc a partir de fonts directes àrabs (GLICK, 2003: 369378; GUINOT, 2007). Els dos primers els trobem adoptats amb una simple traducció literal del seus nom en les ciutats d'Andalusia i Múrcia posteriors a la conquesta castellana d'aquests territoris: són l'alcalde o juez de aguas $(=q \bar{a}$ di al-miyāh $)$ i el fiel de aguas (=amīn al-māa). De fet, fins i tot els tenim documentats amb aquests noms a les viles d'Oriola i Elx, atenent que durant el segle XIII formaren part del regne de Múrcia i la seua colonització fou organitzada pels castellans (PARRA, 2013; IBARRA, 1914; Verdú 2011). Als territoris de la Corona d'Aragó, però, no en tenim notícies. D'altra banda, el muhtasib (el mostassaf valencià i almotacén castellà), un oficial d'origen almohade i per tant d'aparició més tardana, gaudia de les competències 
sobre l'urbanisme i la vida quotidiana a les ciutats, cosa que incloïa la circulació de les aigües pels recintes urbans. Per tant, existeix una clara diferenciació amb els altres dos càrrecs esmentats, perquè aquest sembla centrar-se en la gestió de l'aigua exclusivament a l'interior de la ciutat (GUINOT, 2007).

Però el que ens interessa ara és el șăhib al-sāqiya (el sabaséquia o zabacequia de les fonts catalanes i aragoneses), perquè és clarament d'on procedeix el sequier valencià medieval i modern. Segons Glick (2003: 369374) no hi ha notícies sobre ell a les fonts àrabs, tot i que és clara la seva similitud amb altres càrrecs del món andalusí i també islàmic en general, que s'ocupaven de supervisar diferents àrees sota la jurisdicció del qādi o jutge principal de la mādina: entre d'altres, per exemple, el șăhib al-sūq, que era el policia/jutge del mercat, el șăhib al-šurța, que era el policia/jutge per als delictes, i el șăhib al-madīna, que era una espècie de policia/jutge urbà, el zalmedina o çavalmedina de les fonts castellanes, ja que també el van adoptar a les seues ciutats. De fet, a l'Islam no hi ha separació entre la šurța i la justícia, per això el $q \bar{a} d i$ i els seus subordinats tenen aquesta doble funció i dicten la sentència igual que l'executen (GuICHARD, 2001: 457). Així doncs, tot i que no en sabem res concret per fonts directes, es pot deduir que el șăhib al-sāqiya andalusí devia tenir igualment unes funcions de policia/jutge sobre les aigües i les séquies de regadiu, equivalents a les del muhtasib i la resta de càrrecs jurisdiccionals que porten l'apel.latiu de șăhib. Això és, supervisar el compliment de les normes sobre aigua i irrigació, i en el seu cas jutjar i multar els infractors.

Les fonts documentals que esmenten el șăhib al sāqiya en la seua versió cristiana estan referides bàsicament a la Vall de l'Ebre i a la Catalunya Nova durant el segle XII, i també a València i Múrcia durant el XIII, la qual cosa, en principi, sembla restringir la seua difusió a la part més oriental de la Península Ibèrica; això és, al Targ al-'Ala i al Šarq al-Andalus. La carta pobla d'Alcanyís del 1157, al regne d'Aragó, institueix un zabacequia, i també la d'Horta de Sant Joan, al Matarranya, el 1165. Del mateix segle hi ha referències al zabacequia en els nuclis urbans més grans de la vall, com ara a Tudela (Navarra), a Ricla, i en la ciutat de Saragossa, càrrecs que perduren durant la baixa Edat Mitjana i Moderna com els encarregats de dirigir els sistemes de reg locals, formant part alhora dels membres que componien el consell municipal corresponent (SARASA, 1989; 2008). Finalment al Fuero de Teruel, de 1177, també apareix esmentat, sent aquesta la font més explícita sobre les seues funcions a l'Aragó. ${ }^{6}$

6 "Çavaçequia suo sevicio de unoquoque hereditario habeat II nummos. Similiter çavaçequia habeat terciam partem ommnium calumpniarum que evenerint in açeqiis que mundate non fuerint, iuxta forum. Tanem si illus testimonio, illa calumni colligatur", citat per ORTEGA i LALIENA (2012: 90) 
Pel que fa a Catalunya, sabem que a Tortosa l'encarregat de les aigües de l'horta també rebia el nom de sabaséquia, almenys el 1165 (BONNASSIE, 1991: 260). A Lleida un tal Pere Ramon Sassala era igualment esmentat com a çavacequia en els documents que l'identifiquen com a posseïdor dels drets sobre les séquies de Segrià i de Fontanet, lliurats a son pare Ramon Sassala pel comte Ramon Berenguer IV després de la conquesta de la ciutat (TeIRA, 1968: 94-99). Aquest darrer cas és un clar exemple de privatització feudal de la gestió de la irrigació i del sequiatge, tot i que el 1190 i el 1204 acabés venent els seus drets sobre ambdues séquies a la ciutat. Però tant ell com el seu fill, Pere Sassala, continuaren exercint el càrrec de sabaséquia pels coneixements tècnics que havien adquirit. En qualsevol cas, l'esment és suficient per a indicar-nos que el càrrec devia existir a Lleida en època andalusina, perquè es va anomenar així al seu "substitut" cristià, malgrat els canvis de gestió introduïts pel feudalisme.

En el cas del País Valencià la referència més antiga que es coneix a unes persones encarregades del regadiv es remunten a prop de l'any 1000. Segons Ibn Hayyān, amb la desaparició del Califat de Còrdova, arran de la fitna o crisi del 1009, dos esclavons (saqāliba, sing. șaqlab) amirites, de nom Mubārak i Muzaffar, prengueren el poder local a València i a Xàtiva. Diu el cronista àrab que abans de la fitna aquests dos personatges havien estat encarregats de l'administració de les séquies de reg valencians (wakālat al-sāqiya bi-Balansiya), però sense precisar res més concret.7 Molts autors han vingut a qualificar Mubārak i Muzaffar com a simples sequiers, però és evident que aquesta "administració" en mans d'uns fidels saqāliba al servei de l'estat califal amirita, que fins i tot hagueren d'anar a Còrdova a donar explicacions, no pot ser tan simple. En realitat, el mot wakāla tenia originalment un sentit general de delegació de l'autoritat en una persona de confiança, cosa que quadra molt bé amb la figura dels saqāliba amirites, però en aquest cas sembla més relacionat amb la delegació de l'autoritat judicial, que no d'un govern estatal de les séquies. En qualsevol cas, és difícil precisar si eren uns $a s ̣ h \bar{a} b$ al-sāqiya o algun altre càrrec diferent i superior, de manera que la incògnita resta oberta en aquest sentit.

Cal anar al moment de la conquesta de València per a trobar una referència directa a un șāhib al-sāqiya andalusí amb aquest nom. Així, l'any 1244 esclatà un conflicte per la distribució de l'aigua de reg entre els primers colons cristians que s'acabaven de repartir una part de les terres de

7 La traducció del relat d'Ibn Hayyan en Labarta, Barceló i Veglison (2012: 131), i la cita transliterada del text en àrab està agafada de GLICK (2003: 367), que la va copiar de l'edició d'E. Levi-Provençal. 
I'horta de Gandia. Concretament entre els colons instats vora el castell de Bairén (la vila de Gandia només es fundaria quatre anys després, el 1248) $i$ els assentats a les dues alqueries de Benieto. Tot i que només el coneixem per una còpia tardana, a més a més ara perduda, i que fou escrit en aragonès-castellà per la participació com a jutge d'un alt noble aragonès, Pelegrín de Atrossillo, allò que ens interessa ara és que van fer venir els antics "çavaçequias o moros çequieros" (se'ls anomena indistintament de les dues formes) que s'havien ocupat de la gestió d'aquestes séquies fins al moment de la seva expulsió del castell de Bairén, perquè els explicassen com es distribuïa abans l'aigua entre les diverses alqueries andalusines (СHABÀs, 1898; GUICHARD, 2001: 30). Es tracta, per tant, de la prova documental més clara de l'existència al territori valencià dels aṣhāb al-sāqiya, i ens demostra que entre les seues funcions estava la de repartir i distribuir l'aigua de reg. A més, com hem vist, per la similitud amb els altres așhāb tot sembla indicar que també tenien les funcions de vigilància del sistema, i de jutge de primera instància sobre els infractors.

\subsection{Els primers sequiers cristians $\mathrm{i}$ les seues funcions al segle XIII}

Una vegada produïda la donació de les séquies de l'horta de València als habitants de la ciutat el 1239, es detecten múltiples donacions semblants en altres viles i llocs, gràcies a les cartes pobles. Però no és fins a mitjans del segle XIII que trobem notícies específiques sobre l'existència dels sequiers i sobre les seues funcions. Així, la primera notícia que tenim és un privilegi reial datat al gener de 1250 que regula les funcions dels sequiers de la ciutat $i$ de l'horta de València, que després també es va incloure als Furs. De forma immediata, a la carta pobla de la moreria de Xàtiva, datada al gener de l'any següent, tenim una referència negativa que demostra l'existència d'un sequier cristià en aquesta ciutat, que només havia estat colonitzada des del 1248, ja que se li impedeix l'entrada al raval dels musulmans. ${ }^{8}$ Del 1260 és la primera menció al nom personal d'un sequier, Bonfill, "cequiario et magistro cequie Aliezire", que treballava per a la corona perquè en aquell moment aquesta séquia encara tenia un control reial. ${ }^{9}$ q quan el rei va cedir

8 El privilegi de 1250 en AMV, Pergamins, n. 4, publicat per Cortés (2001), doc. 33. Hi ha autors que el daten incorrectament en 1251. Pel que fa a Xàtiva: "Mandantes quod aliquis cequiarius Xative non intret domos vel ravallos vestros pro aqua petenda vel accipienda nisi cum uno sarraceno ravalli predicti". ARV, Real, reg. 611, f. 275r-276r, publicat per GUINOT (1991: 247-250).

9 Arxiu de la Corona d'Aragó (ACA), Cancelleria, reg. 10, f. 131v, publicat per GuAL (1979: 100). 
la gestió de la Reial Séquia de Montcada als seus hereters, al maig de 1268, els va permetre que nomenaren sequiers amb les mateixes funcions que tenien "in aliis cequiis regni Valencie" -que eren totes les incloses als Furs-, o altres que volguessen afegir ${ }^{10}$

Més tard, Jaume I va intervenir directament en la construcció de la Séquia Major de Vila-real, a la Plana de Castelló, alhora que fundava la vila mateixa. En un privilegi del 1273, quan les obres no havien acabat, el rei va atorgar al noble Guillem Ramon de Montcada les aigües sobrants d'aquesta séquia per a la seua senyoria de Nules, situada geogràficament al final del nou canal, i Jaume I aprofità la cessió per a regular també el seu ús. Així, el document estableix que hi hauria dos sequiers, un nomenat pel batle reial de Vila-real, i un altre pels veïns de Nules que no tindria jurisdicció fora del seu terme municipal." Estem al davant, doncs, d'un model mixt, o a mig camí encara, entre la forma institucional de govern reial i la municipal. Però, en qualsevol cas, pel que ara ens interessa, allò més important és la seua existència, i l'adjudicació d'unes funcions semblants a les d'altres sequiers.

Encara hi ha documentats altres esments de sequiers del segle XIII en altres viles i llocs del regne, però allò que solen tenir en comú és que es tracta de documents que demostren, simplement, la seva existència, però no els mostren encara en l'exercici de les seves competències. Per això és tant significatiu el privilegi reial de gener de 1250 que Jaume I va donar a la ciutat de València sobre les funcions dels sequiers (cequiarum conductores sive cequiarii civitatis Valencie et eius termini, diu el document), que a grans trets ve a coincidir amb allò establert pel mateix rei el juny de 1273 per a la séquia reial d'Alzira. De fet, el privilegi de València es va incloure en els Furs del regne només un mes després, amb uns canvis mínims que eliminaven les referències a la ciutat per fer-lo extensible al conjunt de les viles que ja es regien per ells. Es tracta, concretament, de la rúbrica CXLIII de Jaume I, anomenada "Dels cequiers". ${ }^{2}$

10 "Concedimus etiam vobis et vestris quod possitis ibi ponere cequiarium sive cequiarios ad voluntatem vestram, qui habeant illam potestatem in illa cequia quam alii cequiarii havent in aliis cequiis regni Valencie in quibus sunt constituti ab homnibus terre nostre, vel quamcumque aliam quam vos sicut in re vestra eis duxeritis concendam". ARV, Real 613, f. 216v; AMV, Furs, còdex I c.1-5, publicat per Cortés (2001), doc. 85.

11 ACA, Cancelleria, reg. 873, f. 194v-195r, publicat per Sempere i GARCIA Edo (2003: 93-94).

12 El privilegi del 1250 en AMV, Pergamins, n. 4, publicat per CoRTés (2001), doc. 33. El privilegi del 1273 en AMA, Llibre de privilegis, vol. 36, f. 51r-53r, publicat per GuAL (1979: 105-106). La cita dels Furs segueix l'edició de López Elum (2001). Sobre les Corts de Morella de 1250 que inclogueren el privilegi de València als Furs per a tot el regne vegeu la mateixa obra, pp. 50-59. 
Però, quines eren aquestes funcions? D'acord amb el privilegi de $1250 \mathrm{i}$ la rúbrica indicada dels Furs, les seues funcions es poden classificar bàsicament en tres grups: la neteja dels canals, el manteniment de les infraestructures físiques, i la vigilància del seu correcte ús per part dels usuaris-regants. Pel que fa al primer grup, s'indica l'obligació del sequier d'escurar les séquies a fons una vegada a l'any, ${ }^{13}$ eliminar les males herbes de la séquia, no tornar l'aigua a la séquia després de realitzar aquestes accions fins que els responsables de supervisar el seu treball donassen el vistiplau (al privilegi els supervisors són els jurats de la ciutat, mentre que als Furs no s'especifica) i, finalment, fer i obligar els hereters a escurar els braços i els canals secundaris, cadascú el tros que afrontava amb les seves terres. D'altra banda, les funcions del segon grup eren reconstruir sempre els partidors d'acord amb la forma i les mesures originàries (les andalusines d'abans de la conquesta), reparar les séquies quan es fessen malbé per solsides o avingudes d'aigua, amb el mateix criteri de conservació, i reparar l'assut quan es trenqués (abans de 15 dies a l'hivern o abans de 8 dies a l'estiu segons el privilegi, però abans de 10 dies a l'hivern i 8 a l'estiu segons els Furs).

Finalment, el tercer grup no es presenta com a funcions directes del sequier, sinó com una sèrie de mesures i prohibicions punibles, aplicades als usuaris o regants, com ara no sorregar els camins ni els camps dels veïns, no agafar aigua quan no toca, o desviar-la per altres canals. Cap dels dos documents especifica qui ha d'imposar les multes per l'incompliment d'aquestes normes, però se sobreentén que és el sequier, tant pel context del document com per l'activitat pràctica coneguda en els segles posteriors, que veurem després amb major detall. De fet, la primera vegada que tenim documentada l'existència d'un sequier de l'Horta de València, el 1282, està relacionat amb una multa imposada a un infractor. Es tracta de Simó d'Aldaia, "cequier de la céquia de Torrenz e Quart" laixò és, de Quart i Benàger), qui apareix citat al llibre del Justícia de València perquè després d'haver multat a un tal Ramon Sagrassa, draper i propietari d'una vinya, aquest no va pagar i el sequier li va penyorar 12 alnes de drap llombardesc que un corredor va procedir a vendre per saldar la multa (GUINOT et al., 2008: 362).

D'altra banda, també s'aporten indicacions per als hereters, com ara que es pagués sequiatge per la terra campa però no pels horts i vinyes, i que quan s'arrendassen les séquies quedés establerta la quantitat de sequiatge

13 Al privilegi de 1250 s'empren els verbs purgare i mundare, mentre que el fur en romanç diu escombrar, i no escurar com és tradicional. El privilegi de 1273 també diu "purgacione sive mundacione cequie". 
que caldria pagar per jovada. Aquesta darrera indicació és molt important, perquè ens demostra que des del primer moment es va preveure l'arrendament del càrrec de sequier, que de fet fou allò més habitual en tota l'època foral. Finalment, en aquest sentit, es facultava els hereters per exigir al sequier que comprometés els seus béns amb una fiança, per si no acomplia tot allò estipulat com a obligacions seves. En definitiva, doncs, el que es pot constatar a partir d'aquest privilegi de 1250, i del seu equivalent foral, és que les funcions del sequier eren, al segle XIII, fonamentalment tècniques, de manteniment del sistema, i al marge de qualsevol responsabilitat en el govern institucional o en la política de l'aigua, que restava en mans d'altra gent, com ara els jurats en aquest cas, o els oficials de la corona en altres llocs.

\subsection{L'evolució del model de gestió al segle XIII: sabaséqui- es, sequiers i sobresequiers}

El privilegi de 1250 i la seua inclusió als Furs van deixar clares les funcions dels sequiers per a les localitats que en aquell moment es regien pels Furs de València. Amb tot, aquest no era l'únic càrrec o ofici relacionat $a m b$ el regadiu en el dos-cents. Cal dir que els dos primer furs de la rúbrica CXLIII de Jaume I no apareixen al privilegi de 1250, de manera que, probablement, pertanyen al Costum original que el rei va donar a la ciutat de València el 1238. Significativament, el primer fur no parla de sequiers, sinó de savasequiers, a més en plural, un mot que, com ja hem vist, es deriva del șăhib al-sāqiya andalusí. Aquest fur els adjudica la funció de vigilar les aigües i recórrer totes les séquies del terme de la ciutat de València per a distribuir l'aigua de forma correcta, multar els infractors que furtassen aigua - la conduïssen cap a altres canals, i també als que trencassen les séquies per extraure aigua, sota pena de 60 sous. ${ }^{14}$

Com es pot veure, aquestes no són exactament les mateixes funcions indicades per als sequiers al 1250 que, deixant de banda la capacitat punitiva sobre certes infraccions dels usuaris, parlen bàsicament del manteniment de les infraestructures del sistema. Per contra, aquestes funcions de distribució de l'aigua i vigilància del seu ús, indicades al primer fur de la rúbrica CXLIII, recorden molt a les del șăhib al-sāqiya, d'acord amb les atribucions que se li poden suposar per comparació amb els altres oficials que porten el mot

14 Cal recordar que en el document de cessió dels sistemes de reg als habitants de València el 1239 (vegeu nota 1) el rei indicava als habitants de la ciutat i de l'horta de València que podien regar "secundum quod est antiquitus consuetum". Per descomptat, el 1239 el costum antic era l'andalusí. 
șăhị i també coincideix amb l'única funció que coneixem dels sabasequiers musulmans documentats a Gandia el 1244, que s'ocupaven, almenys, de la distribució de l'aigua. Fins ara s'ha entès que els sabaséquies i sequiers dels Furs eren sinònims, dos mateixos mots per a una sola realitat, i així pareix confirmar-ho el que sabem pel sabaséquies de Terol, en principi de 1177, que sí té la funció d'escurar les séquies. Però és tot molt confús, i és difícil estar segur si són un mateix càrrec 0 dos.

En qualsevol cas, si el fur indicat era, com sembla, immediatament posterior a la conquesta de València el 1238, podem suposar que el rei va adoptar inicialment el model andalusí del șāhib al-sāqiya com a càrrec de gestió de les aigües de reg, que ja havia estat adoptat abans a les ciutats catalanoaragoneses conquerides al segle XII. És possible, fins i tot, si eren diferents, que els sabasequiers tinguessen oficials subordinats, que podrien ser de fet sequiers, però això no deixa de ser una especulació que per ara no es pot comprovar. De fet, si ambdós eren càrrecs diferents la conclusió més lògica és que sequiers i sabasequiers es degueren anar modificant amb el temps fins a fusionar-se, adaptant-se així a la realitat de la nova societat feudal. Per això els sequiers baix-medievals i moderns tenien les funcions que els Furs adjudiquen tant als sabasequiers en el primer fur com les que adjudiquen als sequiers en la resta de furs posteriors de la rúbrica, com veurem amb més detall al següent apartat. De fet, quan al gener de 1273 Jaume I estableix una reglamentació per al funcionament de la séquia reial d'Alzira, llavors encara en mans de la corona, el sequier apareix com un subordinat de la monarquia que només té la funció de repartir l'aigua, i que pot ser supervisat pel consell municipal en defensa dels seus propis interessos. ${ }^{15}$ També és aquest el cas de Nules i Vila-real, que ja hem vist, datat en el mateix any de 1273, on el sequier té un paper tècnic supervisat pel consell o pel batle reial. Així doncs, en aquest moment el nom ja ha canviat, i només existeix el de sequier, que és un càrrec tècnic que té les funcions indicades per al sabasequier en els Furs i del sequier de 1250, però subordinat al batle o als jurats com al privilegi de València.

En el cas de Castelló de la Plana, d'altra banda, en la carta pobla donada per Nunó Sanç el 1239 a l'alqueria de Benimahomet (Banī Muhammad),

15 "Item, in dicta cequia ponemus cequiarium, causa custodiendi dictam cequiam, nostris propriis expenssis; verumtamen vos, homines dicte universitatis, possitis si volveritis ponere ibi, vestris expenssis, unum hominem qui videat si cequiarius quem nos ponemus bene vel male se habeat in eadem. Item, concedimus et volumus quod vos homines dicte universitatis possitis ponere cequiarios vel cequiarium, vestris propriis expenssis, qui custodiat braçallos et dividat aquas, postquam exiverint de cequia iam dicta". AMA, Llibre de privilegis, vol. 36, f. 51r-53r, publicat per GuAL (1979: 105-106). 
quan encara no existia la vila, s'esmenta el terme çabaçequiam, tot i que només per assenyalar que se'l retenia el senyor, cosa força habitual als territoris conquerits fins aquell moment. Al 1283, però, quan el nou senyor, el monestir de Sant Victorià, va atorgar el govern i la jurisdicció de la séquia major als veïns de la vila, ho feu seguint les indicacions establertes als Furs de València, i amb posterioritat a aquesta data ja s'empra sempre el mot sequier, com es pot veure als llibres conservats del segle XV en aquesta vila. ${ }^{16}$

Certament, el terme sabaséquies o sabasequier s'esmenta poc a la documentació valenciana del segle XIII, de manera que semblaria que no degué durar massa. ${ }^{17}$ Però existeix un altre terme, sobresequier, que està més documentat, tot i que mai amb la mateixa freqüència que el de sequier. La major part dels autors que s'han ocupat de la irrigació a les hortes mediterrànies consideren que ambdós mots són sinònims, malgrat tenir una etimologia diferent. Així, mentre és evident que els mots sabaséquies i sabasequier són producte de la fonetització o adaptació del terme àrab șạhib al-sāqiya, per contra el mot sobresequier (o sobreacequiero, com li diven a Múrcia i a la primera documentació castellana d'Oriola) és clarament un neologisme introduït a les llengües romàniques per a referir-se a un oficial municipal que està per damunt dels sequiers. Tot i això, pareix que es tracta certament de dues formes lingüístiques diferents d'adaptar de l'àrab el nom d'un únic càrrec, amb unes mateixes funcions, que és el șạhib al-sāqiya.

A Múrcia i a Oriola el càrrec de sobreacequiero com a oficial municipal va existir des del primer moment, i encara va perdurar fins al segle XVII. De fet, era l'oficial més important en relació amb la irrigació, tal com es manifesta al privilegi donat per Alfons $X$ de Castella a la ciutat d'Oriola el 1275 , en el que no només nomena un sobresequier (a partir de 1295 el nomenament serà anual i el farà directament el consell de la ciutat), sinó

16 La carta pobla de Benimahomet en ACA, Cartes reials de Jaume I, caixa 2, publicat per GuINOT (1991), doc. 34. La donació de la séquia el 1283 en AMC, Pergamins, s/n. Sobre els llibres del sequier de Castelló del segle XV que s'han conservat vegeu GuCK (2003: 114-129) i els comentaris més endavant.

17 Sembla que el mot sabaséquies no va desaparèixer del tot en alguns llocs, ja que així era com s'anomenava, almenys en segles posteriors, als oficials d'alguns canals secundaris de la séquia reial de Montcada, els quals estaven subordinats al sequier, que ho era de tota la séquia Guck (2003: 82). Amb tot, no deixa de ser una reminiscència terminològica que no té res a veure amb el sabaséquies original. Cal assenyalar que l'esment que fa Glick de l'ús del terme sabaséquies a Montcada com a oficial per sota del sequier ha portat alguns autors a creure que aquesta era una situació generalitzada, normalment quan se l'ha comparat amb I'horta de Múrcia, però açò no era així. A Vila-real també existien sabaséquies al segle XV, que eren equivalents als guardes, per sota del sequier (ROMÁN, 2000: 107). 
que també especifica les seues funcions. A Múrcia, per contra, eren dos els sobreacequieros, un per a cada banda del riu, i tenien les mateixes funcions que a Oriola, a més amb acequieros subordinats per a cada séquia. ${ }^{18}$ Però també existia al País Valencià, com ara a Borriana, un oficial municipal que estava, com el seu nom indica, per sobre dels dos sequiers de la vila, que eren un per cada séquia mare del terme. ${ }^{19}$ Cal pensar, però, que Borriana fou una vila poblada a fur d'Aragó, on s'empra aquest terme amb anterioritat, i que no va acceptar els de València fins a 1329, igual que Vila-real.

Durant un temps també va existir un sobresequier a la ciutat de València, però no està gens clar si era una continuïtat dels sabaséquies esmentats ja al Costum de 1238, perquè aquells eren diversos, o més probablement es va introduir amb posterioritat. La majoria dels autors esmenten la seua existència a partir d'un fur de Pere el Gran, que inicialment fou un privilegi per a la ciutat de València que es va aprovar a l'assemblea parlamentària que va tenir lloc el 1283 en aquesta ciutat, on precisament es deroga el càrrec definitivament. ${ }^{20}$ Però existeixen altres esments anteriors i, també, posteriors. Per exemple, sabem que el 1279 aquest mateix rei nomenà sobresequier de tot el terme de València a Joan d'Osca, la qual cosa ja ens indica que aquest oficial no era municipal sinó de designació reial. Que no hi haja cap esment anterior podria indicar que, potser, aquesta fou la primera designació, i per tant el moment en el qual es va introduir el sobresequier a València, però açò ara no es pot confirmar ni ha de ser necessàriament així. En qualsevol cas, sabem que el càrrec fou efectiu uns quants anys, $i$

18 Sobre Oriola vegeu el document complet donat per Alfons X el 1275, publicat per GuINOT (2007), i comentat per PARRA (2013: 479). A Múrcia les funcions del sobresequier al segle XIV eren: "que guarde et procure cuanto pueda el pro y el bien de las açequias y que afinque a los çequieros que fagan tener las açequias, et los braçales, et los açarbes mondados; et que partan las aguas et usen según la partiçión que fizo et fará el concejo, et que tengan las carreras et puentes derechos, et si los çequieros y cogedores de los çequiages ovieren menester ayuda en algunos que fallaren rebeldes, que el sobreçequiero vaya allá et que les prenda et les faga pagar et complir lo que devieren et que oyan et libren todos los pleytos et contrastes que acaesçieren entre los çequieros o cogedores de los çequiages con los herederos en razón de las calonias o de los cogidos, et si algunos se agraviaren de los juyzios del sobreçequiero, puédanse alçar entre los jurados et los jurados que lo libren" (TORRES Fontes, 1975:37).

19 Borriana va tenir dues séquies majors separades (la Sobirana i la Jussana) fins el 1407, quan el rei Martí l'Humà va donar permís al consell municipal per unificar-les amb un únic assut per a resoldre els plets per qüestions de captació d'aigua (GUINOT i SELMA, 2001).

20 "Item concedimus, quod supercequiarius de suo officio imperpetuum sit electus, et unusquisque ex cequiariis utatur et uti possint secundum quod erat antiquitus consuetum". Aureum Opus, València 1515, fs. 29v-32v. Sobre açò vegeu el que diu Guck (2003: 76-77). 
amb un cert interès per part de la corona, ja que el 1282 era l'infant Alfons qui ordenava al justícia de València que permetés al sobresequier Pere Mercader i als seus homes portar armes, la qual cosa no només ens confirma la protecció reial de la seua figura, sinó que a més també ens informa que el titular ja havia canviat tres anys després, que aquest tenia certs homes al seu servei (que no pareixen ser els sequiers, sinó alguna mena de lloctinents o guardes), i que existia alguna conflictivitat social en aquell moment que els obligava a portar armes en l'exercici de les seues funcions. Clar que no sabem quines eren aquestes funcions, tot $i$ que es pot suposar que no serien molt diferents a les dels sobrecequieros murcians. ${ }^{21}$

Com ja hem vist, a l'assemblea parlamentària de l'any següent, el 1283, el rei es veié obligat a derogar el càrrec de sobresequier de València mitjançant un privilegi. De fet, es va aprovar juntament amb un ampli ventall de privilegis per a la ciutat-que més tard s'inclourien als Furs dins de l'anomenat Privilegium Magnum per estendre'ls a les altres viles regides pels Furs de València- a canvi de l'aprovació d'un subsidi pecuniari per a finançar la defensa de la Corona contra la invasió francesa de l'any següent, que ja es preveia en aquell moment. El context general d'aquella assemblea, doncs, en la que clarament es va intentar beneficiar a tots els grups socials d'aquesta ciutat, ens confirma que el sobresequier de designació reial no agradava a l'oligarquia urbana que dirigia els òrgans de govern municipal, i a banda tot pareix indicar que el sobresequier de la capital no devia existir des de feia molts anys. Així, el mateix text del privilegi-fur de 1283, adés citat, deixa clar que els sequiers tornarien a exercir les seues funcions anteriors, "secundum quod erat antiquitus consuetum".

Tanmateix, immediatament després de l'aprovació d'aquest privilegi encara tenim documentat al sobresequier actuant a la ciutat. En el llibre del justícia de València de 1284 apareixen citats el sequier de Rascanya, Guillem de Monsó, i el sobresequier, Pere Mercader, els quals havien imposat una multa a un tal Quintana, que sembla carnisser. Com que l'infractor no va pagar, i per això apareix reflectit en aquesta font, sequier i sobresequier li van penyorar una conca d'aram i un cobertor de lli, els quals foren lliurats a un corredor, que va procedir a vendre'ls (GREGORI et al., 2008: 803). Tot plegat ens informa, en primer lloc, que el sobresequier encara era el mateix personatge que va rebre permís per portar armes el 1282, i a més ens indica que al maig de 1284 el privilegi reial derogatori de desembre de l'any

21 El nomenament de Joan d'Osca el 1279 està en ACA, Cancelleria, reg. 44, f. 157. El document que dóna permís a Pere Mercader per portar armes del 1282 està en ACA, Cancelleria, reg. 59, f. 152v. Sobre les funcions dels sobreacequieros mucians vegeu dalt la nota 18 . 
anterior encara no s'havia fet efectiv i el sobresequier seguia existint. Però no per molt de temps, segurament.

Pel que fa a les altres viles, sabem que a Castelló de la Plana també hi havia hagut un sobresequier, almenys al voltant de 1279, puix en aquest any el rei va ordenar a l'antic batle reial de la vila que pagués a Esteve de Concabella el que li devia pel temps que havia exercit aquest ofici per ordre seva. ${ }^{22}$ Per tant, és probable que la introducció del sobresequier fos generalitzada a totes les viles reials. Però posteriorment no hi ha cap altra notícia, cosa lògica si pensem que amb la inclusió del privilegi de derogació a la ciutat de València en els Furs, es va generalitzar a totes les localitats regides pels Furs de València.

La conclusió de tot plegat, doncs, pareix ser que Jaume I adoptà per a València el model del șāhib al-sāqiya després de la conquesta de la ciutat el 1238 (independentment de l'existència o no d'aquest càrrec a la Balansiyya post-almohade), amb la funció de distribuir l'aigua de reg entre les séquies i perseguir les infraccions que tenien relació amb el seu ús. Possiblement, o no, a banda hi haurien també uns sequiers que tindrien la funció de mantenir els canals, cobrar el sequiatge i perseguir les infraccions que tenien a veure amb danys sobre les infraestructures, que són les mateixes funcions que se'ls adjudica al privilegi de 1250; però açò no és del tot segur. De fet, aquest és el mateix model que tenia Borriana, conquerida cinc anys abans que València. Amb tot, en un moment indeterminat, però posterior a 1250, pareix que el mot sabaséquies desapareix, $\mathrm{i}$ els sequiers queden investits d'una major autoritat que la que tenien als Furs. Aquest és el model que més tard es consolidaria a l'horta de València, i el que adoptarien moltes viles $\mathrm{i}$ llocs de conquesta i colonització més tardana com ara Xàtiva i Gandia, o bé amb sistemes hidràulics de nova construcció, com ara Alzira i Vila-real.

Encara així, en algun moment igualment indeterminat, però que deu estar al voltant dels anys setanta del dos-cents, València va tenir un únic oficial de designació reial per controlar la irrigació, amb el nom de sobresequier, i amb poder per damunt dels sequiers. Possiblement per influencia del model castellà de Múrcia i Oriola, que és molt semblant i que es va establir als mateixos anys setanta. I encara que tenim molt poques referències, sabem que va existir alguns anys, fins que el 1283 el càrrec fou derogat per voluntat de la ciutat, i les seues funcions foren assumides de nou pels sequiers, tal i com havia estat acostumat anteriorment. Fins a quin punt l'assumpció d'aquest model més centralitzat a la capital va influir a la resta de viles reials és difícil de precisar, però l'existència d'un sobresequier a Castelló pareix apuntar en 
aquesta direcció. A l'horta de Xàtiva, per la seua banda, de la que tenim molt poca informació per la pèrdua de l'arxiu de la ciutat, el 1416 encara s'esmenta en un plet un sequier i un sobresequier de la séquia de Rahana, a Rotglà. ${ }^{23}$ Per tant, és difícil pensar que al segle XIII no existissen ja, però amb tan poques dades no és possible arribar a cap conclusió definitiva sobre l'aparició, evolució i desaparició d'aquest càrrec.

\section{La consolidació del seQuier entre els segles XIV I XVI}

Si per al segle XIII hi ha poques notícies sobre el sequier i altres càrrecs $\mathrm{i}$ oficials relacionats amb la gestió de la irrigació, per al XIV encara en tenim menys. D'una banda, perquè la legislació que regulava les seues funcions ja havia quedat ben fixada i definitivament consolidada des de finals del segle XIII, tant als Furs com als possibles privilegis particulars de diverses viles i llocs, per tant ja no se'n va fer de nova. Només algunes viles generaren normativa nova sobre irrigació entre els diversos establiments que anaven aprovant els consells municipals, però sempre basada en la legislació foral i mai no directament sobre les funcions del sequier. D'una altra banda, tampoc no hi ha documentació de l'exercici pràctic de les funcions del sequier perquè sembla que no va deixar-hi rastre encara en aquesta centúria, tot $\mathrm{i}$ que també podria ser que no se n'haja conservat, o que no s'haja investigat suficientment.

L'única excepció que tenim per a aquest segle és l'arrendament per cinc anys de la séquia de Vila-real a dos sequiers en 1307, i gràcies a l'ús del seu pergamí com a coberta d'un registre més tardà. En qualsevol cas, en aquest document es pot confirmar que l'arrendament el fan els jurats i el consell de la vila, i que les funcions dels sequiers en l'exercici del càrrec són similars a les que s'expressen als Furs. Bàsicament es tracta d'escurar i herbejar la séquia, mantenir l'assut, i distribuir l'aigua segons era costum. Si cometien frav en aquesta darrera activitat serien sancionats amb 60 sous, que és la xifra que assenyalen els Furs, i per descomptat posaven els seues béns particulars com aval si no acomplien correctament les seues funcions. ${ }^{24}$

En el segle XV la informació ja és més abundant, i per primera vegada trobem normativa específica amb més detall sobre les funcions i les obli-

23 ARV, Governació, 2214, mà 7, f. 46r-v; 2215, mà 12, f. 2r-v; mà 14, f. 32r-v; 47r-48v; mà 15, f. $23 r-28 v$.

24 AMC, Claveria, 208 (contraportada), publicat per GARCIA Edo (1994: 132-134). Cal deixar clar que la forma del document no és gens explícita, i que sense conèixer altres arrendaments del segle XV aquest de 1307 sembla un nomenament directe. 
gacions dels sequiers, especialment a les comunes de l'Horta de València. Així, es constata una gran similitud entre la normativa existent, tant entre les diverses comunes, com amb altres localitats del regne, i també entre elles. Del model municipal els llocs millors coneguts són per ara Castelló i Vila-real, estudiats respectivament per Thomas Glick (2003: 114-129) i Immaculada Román (2000), ja que en ambdós casos els arxius municipals conserven llibres de registres i diversa documentació complementària. En altres viles també tenim, com dèiem, els establiments municipals del consell, que eren els que tenien la competència sobre el regadiu, tant del segle XIV com del $\mathrm{XV}$ i del XVI, com ara a Gandia, Alzira, Vila-real, etc. ${ }^{25}$ En aquest cas, però, no es tracta tant de les obligacions del sequier, sinó de la regulació de l'ús del sistema hidràulic per part dels usuaris i les multes que havien d'imposar els sequiers locals. De fet, cal dir que la majoria dels establiments són prou repetitius al llarg dels anys -en realitat, com tots els establiments locals sobre qualsevol tema-, la qual cosa indica que les infraccions menors eren força habituals a tot arreu. I, en qualsevol cas, no deixen d'estar basades en la legislació dels Furs com a marc legal comú del regne.

Per a l'Horta de València no hi ha registres seriats, puix la documentació generada per les comunes autònomes del poder municipal de la capital era escassa $i$, en qualsevol cas, es registrava davant del notari, de manera que la poca documentació conservada està molt dispersa en protocols i és difícil de trobar. Per a la primera meitat del segle XV coneixíem tres arrendaments de séquies, en els que s'incloven els capítols, és a dir la normativa específica de cada séquia que estableixen les obligacions del sequier, així com les normes d'ús i repartiment de l'aigua, en la que aquest ha de basar-se per a regir i multar els infractors. És el cas de l'arrendament de la séquia de Mislata a Jaume Gisbert el 1415, l'arrendament de la séquia de Benàger i Faitanar a Bononat Prats el 1421, i l'arrendament de la mateixa séquia a Pere Torres el 1435.26

25 Vegeu els establiments de les viles de Gandia (GarCIA-Oliver, 1987), Alzira (LAIRÓn, 2001) i Vila-real (GIL VICENT, 2002).

26 L'arrendament de Mislata en Arxiu del Col.legi del Corpus Christi de València (ACCV), Protocols, n. 6418, notari Domingo Barreda (2-4-1415), publicat per FEBRER (1985-86). El primer arrendament de Benàger en ARV, Protocols, n. 2864, f. 22 i ss. (6-4-1421); i el segon arrendament de Benàger en ACCV, Protocols, n. 23.682, s/f, notari Francesc Vilba (29-5-1435). Cal dir que en el mateix protocol on està registrat l'arrendament de Mislata n'hi ha més documentació d'aquesta séquia en el mateix període, que ha estat estudiada per Martínez SanMartín (en premsa). 
Sembla que al període medieval no existia cap mena d'ordenances o estatuts de la comuna com els que han estat en vigor a partir del segle XVIII fins a l'actualitat. Al contrari, els capítols aprovats per a l'arrendament del sequier pareixen tenir únicament validesa legal per a la duració d'aquest contracte. ${ }^{27}$ Amb tot, és evident que es copiaven cada any els mateixos capítols, manifestant-se una gran estabilitat normativa, i s'afegien al final els capítols nous que anava aprovant l'assemblea dels hereters. De fet, en el cas de Benàger el 1435 n'hi ha vuit capítols més que a l'arrendament de 1421, i alguns del que ja hi estaven abans s'havien modificat lleugerament. Aquest era el cas també dels capítols de la séquia de Favara. Tenim uns datats el 1446, que s'han conservat perquè foren copiats el 1490 a l'inici del llibre d'actes de la comuna pel notari que en feia d'escrivà. ${ }^{28}$ Encara que no tenim l'acta original de l'assemblea de Favara que va tenir lloc el 1446, i que els capítols estan copiats en un altre context, l'encapçalament deixa ben clar que en el seu dia foren aprovats en una situació semblant a la dels altres arrendaments, ja que es tracta dels "capítols fets per lo comú de la céquia de Favara ab los quals lo cequier qui en les festes de Pasqua de Resurrecció del any de la Nativitat de Nostre Senyor Déu M CCCC XXXX VI trau la céquia de Favara se ha.regir lo temps per lo qual traurà la dita céquia". Açò vol dir que, tot i haver estat aprovats per a l'arrendament d'un sequier per un període concret, en la pràctica tenien intenció de ser perdurables. A més, s'anaren afegint els capítols aprovats a diverses assemblees fins a 1519, alguns per un altre notari posterior. D'altra banda, cal dir que també s'han conservat en un plet de 1599 altres reculls de capítols de Favara datats en 1496, 1564 i 1597, gràcies als quals podem conèixer bé l'evolució de la normativa en les comunes fins a finals del segle XVI. ${ }^{29}$

27 El fet que els dos primers capítols de l'arrendament de Mislata el 1415 facen referència a unes obres puntuals que calia fer a l'assut en aquell moment pareix evidenciar que aquests capítols només estaran en vigor durant el temps de l'arrendament del sequier indicat. Al capítol 1 diu "Primerament, que la canal del cap del açut, que.s tanque quatre o cinch pases d'argamassa, e les messions que.s faran per tancar lo dit açut, e per alcunes altres messions, que.s faça taxa convinent a coneguda de dos prohomens". Al capítol 2 diu "que la dita canal sia closa de larch a larch d'argamasa". També el capítol 30 parla de conflictes concrets d'aquell any quan diu "com de pochs dies ençà alcuns hereters hajen sabut certament que alcunes heretats en la céquia e regants de aquella, se dient esser franchs de cequiatge...".

28 ACCV, Històric, VAR-201, fs. 7r-10v. Sobre aquest llibre d'actes, que conté diversa documentació generada per la comuna de Favara entre finals del XV i principis del XVI, excepcionalment agrupada en un sol volum pel notari-escrivà, vegeu l'estudi de L.P. Martínez Sanmartín i V. Terol (en premsa).

29 ARV, Processos de Madrid, H-16. N'hi ha també una còpia dels capítols de 1446 citats a la nota anterior. 


\subsection{L'elecció del sequier baix-medieval i les seues funcions}

L'elecció del sequier solia fer-se amb una subhasta quasi sempre, tot $i$ que de vegades podia ser designat directament per la comuna o pels responsables de la irrigació als municipis. Així, en el model de govern municipal la designació del càrrec la feien de vegades els jurats, com ara a Castelló, on sembla que era usual la designació directa pel consell a principis del segle XV, i encara a partir de 1472 es va introduir la insaculació (GLICK, 2003: 91). De forma semblant, a Gandia hi havia dos sequiers, un per cada sistema hidràulic: al sequier dellà lo riu (de la séquia de l'Alcoi) l'elegien els hereters en presència dels jurats, sembla que sense subhasta, i al sequier deçà lo riu (de la séquia del Vernissa) l'elegien de la mateixa manera fins que el 1437 el duc de Gandia va ordenar que s'elegís també per insaculació, degut al "scàndel e inconvenient massa grans", a partir d'una llista de noms imposada pel propi duc (CASTLLO, 1997: 52 i 92). A Sueca, una comunitat rural més petita que les viles reials, la documentació del XVI indica que el sequier era elegit pels jurats, i a banda existia el càrrec de recollector del sequiatge, el qual sí s'arrendava en subhasta de vegades (FURIÓ, 1982: 31).

Per contra, a Vila-real allò més habitual al segle XV era l'arrendament del sequier amb subhasta, i no hi ha massa dubtes que fou també així al segle XIV, puix ja hem vist adés l'arrendament de 1307 a dos sequiers (tot i que no es diu com els han elegit) i el $1380 \mathrm{n}$ 'hi ha indicis que apunten en aquesta direcció (ROMÁN, 2000: 105). Finalment, en el cas de les comunes de l'Horta de València, tot i que l'assemblea dels propietaris o hereters podia elegir i nomenar directament el sequier en situacions excepcionals, com ara per fer grans obres, allò normal al XIV-XVI era la subhasta i arrendament del càrrec, tal com estableixen els Furs. Així, per exemple, la comuna de Benàger i Faitanar justificava l'arrendament de la séquia el 1421 que ja hem esmentat adés en "fori disposicionem et ex antiqua consuetudine".

Però, en què consistia aquesta subhasta i arrendament? El manteniment i neteja de les infraestructures comunes de la séquia era una obligació collectiva dels propietaris de les terres irrigades pel sistema. Així, la xarxa secundaria de séquies la mantenien els propis usuaris (que no necessàriament propietaris) en netejar els trams que afrontaven amb les terres que posseïen o treballaven. Però per al manteniment de la xarxa principal -l'assut, els partidors i la séquia mare- el que feien els hereters de la comuna o els veïns del municipi, segons el cas, era pagar una quantitat variable en moneda, que estava en relació amb la superfície posseïda, per a les despeses: el sequiatge. Aquesta aportació tenia segurament un origen andalusí, ja que s'assembla molt a la sukhra per al manteniment col.lectiu dels castells rurals i les muralles urbanes (GuICHARD, 2001: 364). I sabem que durant els segles 
XII i XIII aquesta aportació es convertí a molts llocs en renda feudal, quan fou privatitzada pels senyors. ${ }^{30}$ Però a partir del segle XIV, i molt probablement ja uns quants anys abans, açò no era així, puix el manteniment constant que requerien l'assut i els canals obligaven a disposar a sovint de grans quantitats de diners que calia extraure del sequiatge necessàriament. ${ }^{31}$

Així doncs, el que feia la comuna o el municipi era arrendar el càrrec de sequier, que era l'encarregat de recollir el sequiatge i pagar les despeses d'escura i manteniment. Es feia així una subhasta o encant, i qui oferia ferho per menys diners la guanyava, sent anomenat immediatament sequier. A Vila-real la subhasta durava mentre romania encès un ciri, el mateix mètode que amb la resta de taxes municipals que s'arrendaven, i en 1484 el consell va incloure una clàusula per la qual podien rebutjar al guanyador si els jurats no el consideraven adequat per al càrrec (ROMÁN, 2000: 108-9 i 113).

Els Furs exigien que en el moment de l'elecció s'especifiqués clarament quants diners haurien de pagar els hereters per jovada posseïda; i als documents d'arrendament de l'Horta es veu que, efectivament, es feia així, tot i que per cafissada a causa de la disminució de les heretats amb el pas del temps. La diferència entre els diners recollits del sequiatge, i les despeses finals realitzades en el manteniment del sistema, era el benefici econòmic del sequier, que es veia augmentat per la part que li corresponia de les multes de les infraccions. Els capítols normatius, doncs, deixen molt clar quina mena de despeses extra devia pagar el sequier, com el dinar del síndic el dia de la visita i supervisió de l'escura, o els serveis del notari per exemple. Però també el lliuraven de realitzar grans pagaments, com ara obres

30 És el cas que hem vist adés a Lleida (TeIRA, 1968). En els anys en els que Jaume I va conservar les séquies de Montcada i Alzira sabem que gastava part del sequiatge en finançar altres assumptes. De fet, el 1266, dos anys abans de cedir la séquia de Montcada als seus hereters, Jaume I va donar a Nicolau de Vallvert de forma vitalícia el sequiatge i tots els dominis reials sobre la séquia (ACA, Cancelleria, reg. 15, f. 12v). El 1271 va cedir al noble Hug de Baus 2.000 sous anuals del sequiatge de la séquia d'Alzira (ACA, Cancelleria, reg. 16, f. 235 i 236v), i el 1276 gastava diners del sequiatge d'aquesta mateixa séquia en les obres de la residencia reial d'Alzira (ACA, Cancelleria, reg. 22, f. 69v). Per contra, el 1286 Alfons III va manar al batle d'Alzira escurar la séquia amb els diners del sequiatge, com havia quedat establert a la concòrdia entre el rei els habitants de la vila (ACA, Cancelleria, reg. 67, f. 107v). La senyoria de Quart de Poblet, a l'horta de València, també es quedava el sequiatge com a renda el 1273, quan el rei els va haver d'obligar a pagar una reparació després d'una avinguda (ACA, Cancelleria, reg. 21, f. 79v).

31 En 1291 el rei recordava al batle de Vila-real, quan el govern de la séquia encara estava en mans de la corona, que els diners del sequiatge eren per al manteniment i escura de la séquia. ACA, Cancelleria, reg. 85, f. 125v, publicat per (RoMÁN, 2000: 247). 
a l'assut per damunt d'una xifra concreta, o la reparació d'infraestructures destrü̈des durant una guerra amb rei estranger.

Pel que fa a les funcions concretes del sequier, es confirma que són les mateixes dels Furs establertes per Jaume I en 1238 i 1250, tot i que és evident que cada séquia particularitza aquestes funcions bàsiques amb l'esment dels trams concrets de la séquia mare que cal que el sequier escure, o les quantitats que cal imposar com a multa o penyora per cada infracció, que són diferents segons la infracció i la comuna, i també diferents de la xifra genèrica de 60 sous de la que parla el fur corresponent de la rúbrica CXLIII. A més, s'estableix la manera com aquestes calònies seran repartides entre el sequier, l'acusador i el comú (o el consell municipal), cosa que els Furs no assenyalen.

En definitiva, doncs, el que es pot deduir dels capítols conservats del segle XV a l'Horta de València, i dels establiments dictats pels consells municipals d'algunes viles des del segle XIV endavant, és que el sequier baix-medieval tenia una quàdruple funció: com a encarregat de l'escura i el manteniment general de la séquia i de l'assut, com a distribuïdor de l'aigua entre els braços, com a policia vigilant del compliment de les normes per part dels usuaris amb capacitat punible i, finalment, com a jutge d'aquestes infraccions. ${ }^{32}$ La principal diferència amb les funcions establertes als Furs $\mathrm{i}$ el privilegi de 1250 és la funció judicial, que allí no queda explícita malgrat que es pot arribar a intuir. En qualsevol cas, aquesta funció la veurem amb més detall en un altre subapartat específic. Pel que fa a la nòmina d'infraccions previstes als capítols, el ben cert és que s'assembla bastant a les denúncies que s'han fet al llarg del segle XX en el Tribunal de les Aigües de València $O$ en altres jutjats d'aigües, ja que estan basades en normes de sentit comú en un context d'acció col.lectiva per a regular el repartiment de l'aigua entre tots els usuaris, i evitar els danys en les terres dels altres o en les infraestructures comunes, com ara el propi caixer de la séquia o els camins. ${ }^{33}$

D'altra banda, una vegada el guanyador de la subhasta era nomenat sequier, i jurava el càrrec davant dels jurats en el model municipal o davant del governador del regne en el cas comunal de València, aquest podia $\mathrm{i}$ de fet solia nomenar diverses persones, a costa seva, perquè l'ajudassen en el compliment de les seves obligacions més pràctiques i habituals. Entre

32 Vegeu també el que diu GııK (2003: 74-86) del sequier a partir de l'estudi de diversos plets del segle XV extretes de Governació i de documentació de Castelló de la Plana.

33 Vegeu també les aportacions de GuIK (2003: 111-137) al respecte de les infraccions a partir dels llibres del sequier de Castelló en el segle XV. 
ells un o diversos lloctinents que s'ocupassen de tota la séquia o de zones concretes; ${ }^{34}$ o perquè el substituïssen en algunes ocasions, els quals havien de jurar el càrrec al seu davant o de vegades davant del Governador com ho feia el mateix sequier. També solien nomenar un guarda perquè l'assistís en la vigilància i detecció de les infraccions, i un "partidor" de l'aigua per a cada braç principal (en època moderna conegut com atandador), que tenia la funció de distribuir els torns de reg entre els regants d'un mateix braç, la feina del qual era especialment important en temps de sequera, quan hi havia poca aigua i la conflictivitat era creixent.

Tanmateix, els sequiers no tenien carta blanca per a actuar. Els Furs ja indicaven que el treball dels sequiers estaria sota la supervisió dels jurats de la ciutat. I encara que això, evidentment, canvià molt prompte a València, i per això existeixen les comunes, el ben cert és que a la resta de viles $\mathrm{i}$ llocs, reials o senyorials, amb un govern municipal dels sistemes de reg, els jurats continuaren exercint aquesta funció, la qual delegaven normalment en altres persones. Així, tal com indicaven els primers privilegis de Jaume I per a les séquies reials d'Alzira i Vila-real, els veïns podien nomenar certes persones que els representassen per vigilar el seu treball. En les comunes de I'Horta de València als segles XIV, XV i XVI aquesta funció de vigilància i supervisió del treball del sequier corresponia a síndich e vehedors, tal com s'indica a l'arrendament de Mislata de 1415, en la que es nomenà un síndic $\mathrm{i}$ sis veedors. També a Favara n'hi havia un síndic i onze veedors, un per cada nucli de poblament o partida d'habitat dispers. La funció del síndic de la comuna, respecte al sequier, era la de supervisar l'escura de la séquia mare, les necessitats de l'assut, i qualsevol altra acció del sequier. Pel que fa als veedors, havien de supervisar el sequier en cadascun dels seus respectius braços o zona d'actuació, així com acompanyar el síndic en la supervisió de l'escura de la séquia mare, i també aconsellar el sequier als judicis. En definitiva, doncs, eren una espècie d'inspectors com els va anomenar Thomas Glick (2003: 84). A canvi, tots ells serien francs del pagament del sequiatge mentre durés el seu mandat, que podia i solia allargar-se uns quants anys.

\subsection{La funció judicial del sequier}

Hem decidit tractar a banda la funció judicial del sequier per la particularitat que representa entre la resta de les seves funcions. D'entrada, no està

34 A Favara i a Benàger, i per tant segurament a totes les comunes, era un lloctinent per cada lloc de senyoria. Vegeu els capítols citats de 1446 i 1432 respectivament, a les notes 28 i 26. 
gens explícita als Furs, tot i que, coneixent bé les funcions del sequier entre els segles XIV i XVI que ja hem vist adés, es podria arribar a sobreentendre que sí que existeix ja en la legislació foral del segle XIII. Amb tot, és molt dubtós, i no sols per a l'historiador actual, sinó també per als contemporanis, per la qual cosa hi havia contínuament confusions i intromissions en les seues jurisdiccions. Així, el 1318 Jaume II va manar al justícia de València que no molestés els sequiers en la seua jurisdicció, i el 1321 va haver de fer el mateix amb el batle general del regne de València. De fet, encara el 1339 Pere el Cerimoniós havia d'insistir en el cas dels jutges sobre la jurisdicció dels sequiers en els plets sobre aigües. I no sols era a València, també en altres viles es van donar queixes per les ingerències dels batles reials en els assumptes de reg, i per això el 1446 un privilegi a diverses viles com Vila-real, Castelló, Morella i Llíria els va confirmar la seua jurisdicció sobre el sequiatge als jurats. ${ }^{35}$

Sobre aquesta confusió, cal tenir present que, com hem vist adés, la legislació que contenen els Furs sobre els sequiers, la rúbrica CXLIII, es va fer probablement en dos moments diferents. D'una banda està el primer fur, donat el 1238, en el que es parla dels sabaséquies sense una major precisió de les seues funcions, i després la resta de furs de la rúbrica que parlen dels sequiers, afegits el 1250 a partir d'un privilegi que inicialment era només per a la ciutat de València. És probable que la funció jurídica dels sequiers baix-medievals provingués del sabaséquies, és a dir, del șāhib al-sāqiya andalusí. Ja hem vist que tots els oficials andalusins que portaven l'apel.latiu de șạhib tenien una doble funció policial i judicial en els seues respectius àmbits d'actuació, sempre per sota del $q \bar{a} d \bar{\imath}$ general que era la màxima autoritat judicial de la madīna i del territori que en depenia. ${ }^{36}$ Aleshores, és probable que al Costum de València de 1238 aquesta funció la tingueren els sabaséquies, i no els sequiers d'aquell moment, per això no s'especifica entre les seues funcions; de la mateix manera que a Múrcia i Oriola la funció judicial la té el sobresequier municipal, i no els sequiers

35 Tots aquests privilegis apareixen recollits als capítols 17, 19 i 24 de les ordenances de Montcada; vegeu JAUBERT DE PASSÀ (1844: 168 i 171). El privilegi de 1446 és citat per ROMÁN (2000: 104).

36 Cal recordar que l'únic document escrit en àrab que conservem d'abans de la conquesta és la sentència d'un plet d'aigües entre dos alqueries, Càrcer i Torres, al terme de Sagunt, dictada pel qā dị de Murbītar el 1223. Però no estem parlant d'un conflicte entre regants, sinó entre alqueries, per això la sentència directa del qādī. ARV, Processos de Madrid, S-429. Actualment està exempt en ARV, Pergamins àrabs, n. 1. 
particulars de les séquies. Però més tard, en desaparèixer el sabaséquies, els sequiers la van adquirir sense que la legislació foral es veiés modificada. D'ací la confusió jurisdiccional.

Si ens fixem en els capítols inclosos en l'arrendament de la séquia de Mislata del 1415 i en el de la séquia de Benàger del 1421, tampoc no diven res del paper del sequier com a jutge. Amb tot, es pot deduir fàcilment que quan s'obliga el sequier a recórrer la séquia setmanalment, junt als veedors i al síndic, no és sols per veure si n'hi ha desperfectes, sinó també per fer de policia contra les infraccions de l'ordenament establert als capítols i, si s'escau, jutjar l'infractor allí mateix. Els capítols de Benàger de 1435, per contra, són més explícits, puix diven que les penes imposades pel sequier als infractors es deuen executar i jutjar a la plaça de la Seu de València, que a més, com sabem, posteriorment serà també el lloc de reunió del Tribunal de les Aigües.37 Els capítols de Favara de 1446 també són molt explícits, indicant que els judicis als infractors calia fer-los al davant del sequier i dels veedors, i afegeixen que la sentència no es pot apel.lar a instància superior.38 Però no s'indica cap lloc específic per a fer els judicis, puix és evident que la majoria es devien fer in situ en el moment en què l'infractor era descobert pel sequier o els seues ajudants, i si n'hi havia un conflicte entre regants faria el judici en acudir a veure el problema. Amb tot, també és evident que el sequier no podia trobar sempre els infractors personalment, per això tenia lloctinents. A més, hi havia denúncies que el sequier rebria per part dels altres regants perjudicats, de manera que devia existir un lloc concret on celebrar els judicis o "tenir cort" al marge de les accions diàries.

En aquest sentit, és ben conegut el document aportat per Glick, de 1418, en el que s'indica que una sentència dictada oralment pel sequier de Favara fou posada per escrit a petició del demandat el següent dijous a la plaça de la Seu, davant dels veedors i els interessats. Un altre exemple menys conegut, però molt semblant, és de 1428, quan el sequier de Rascanya dic-

37 Al capítol 43 diu "que les penyores fahedores per lo dit céquier contra los delinqüents se exheguesquen e se hajen a exigir en la plaça de la Seu e de fer lo juhí de aquelles, e no en altre loch". Referència nota 26. T. Guck (1967; 2003: 135) ja va esmentar aquest mateix capítol en el seu anàlisi del Tribunal.

38 El capítol 64 de les ordenances de 1446 diu "que qualsevol hereter de qualsevol ley e condició sia, si havent debat o qüestió sobre los fets pertanyents al cequier per los fets de la céquia, sia tengut de fer juhi davant lo cequier e vehedors e alli determinar la qüestió o debat. E si contrafarà ni altre jutge fins que per aquells sia vist demanarà, sia encorregut en pena de sexanta sous aplicadors la mitat al cequier e la mitat al comú e que la dita pena no puga fer lo cequier gràcia sinó de la sua part". Referència nota 28. 
tà sentència a la plaça de la Seu, en presència d'un veedor i amb el consell d'altres prohoms llauradors. ${ }^{39}$ I la referència més clara al lloc comú judicial és de 1457, quan la descripció d'una discussió se situa "en lo present dia de matí essent devant lo portal dels Apòstols de la Seu de València hon tots matins se acostumen los hòmens de treball e cequiers ajustar". ${ }^{40}$ És a dir, que aquesta plaça era el lloc públic, conegut per tots, on els sequiers de l'horta de València es reunien amb els regants i hereters de les seves séquies. ${ }^{41}$ Fins a quin punt aquest punt de reunió era una tradició que venia des d'època andalusina és una cosa difícil de demostrar.

No és fins els capítols de Favara aprovats el 1597 que apareix per primera vegada esmentada la plaça de la Seu i els dijous a unes ordenances d'aquesta séquia. Un capítol concret del que no sabem la data en que fou afegit però probablement al XVI, exigia als veedors dels cinc primers braços de Favara, al terme de València, acudir a la plaça tots els dijous "allà hon se seurà lo cequier y lo síndich de la dita céquia". ${ }^{22}$ Per tant, no solament se situa per primera vegada a les ordenances el sequier jutjant a la plaça els dijous amb el suport del veedors -tal com ja veiem al document del 1418-, sinó que també s'hi situa el síndic jutjant junt al sequier, un fet que, aparentment, és un costum que no apareix reflectit en cap ordenança anterior.

En qualsevol cas, aquest lloc de reunió no és tan important com el fet que les poques sentències conservades -perquè la majoria es farien oral-

39 El document de Favara en ARV, Protocols, n. 2974, notari Joan Domingo, publicat per Guck (1967). El document de Rascanya en ARV, Protocols, n. 584. D'altra banda, en un conflicte entre dos individus que afirmaven ser ambdós sequiers de Favara, es va ordenar a un d'ells "que no vengués a tenir plaça ni perturbés lo cequier de Favara". Aquesta forma tan curiosa d'esmentar la cort del sequier sembla fer referència a la plaça de la Seu com a lloc de referència conegut per tots. ARV, Governació, n. 4321, mà 2, f. 55r. Vegeu també GUINOT i ROMERO (2007).

40 ARV, Governació, n. 4322, mà 1, f. 13v.

41 El llibre d'actes de Favara confirma aquesta afirmació (Martínez Sanmartín i Terol, en premsa).

42 El capítol 96 de les ordenances de 1597 diu "és ordenat per lo comú de la céquia de Favara que lo síndich vehedors dels sinch braços de la horta de València, ço és, lo del bras de Raujosa y lo del bras de Gisbert y lo del bras de Jesús y lo del bras de les Monges y lo del bras de la Gàbia, que tots estos sinch vehedors sien obligats de ser cada dijous allà hon se seurà lo cequier y lo síndich de la dita céquia, a pena de deu sous per cascuna vegada que hi faltaran". ARV, Processos de Madrid, H-16, f. 536r. D'altra banda, és evident que els veedors, que tenen la funció d'aconsellar el sequier, ja acudien a la plaça molt abans, com demostra el document adés esmentat de 1418. 
ment- demostren com funcionaven els judicis dels sequiers. De fet, no és com funciona el Tribunal de les Aigües dels segles XIX i XX, però això és un altre tema. El sequier sempre oïa a les parts acompanyat dels veedors de la séquia, o $n^{\prime}$ hi ha molts exemples, no sols les sentències que acabem de veure de Favara en 1418 i Rascanya en 1428, o el capítol de Favara anterior a 1597. El 1441 el sequier de Benàger i Faitanar, acompanyat de quatre veedors, qualificats de llauradors, dictà una sentència en el conflicte que tenien una noble $\mathrm{i}$ un burgés de València per dos torns d'aigua per a regar un hort del terme de Xirivella. ${ }^{43}$ Cal recordar que els veedors no formaven part dels arrendaments com el sequier, sinó que eren elegits per l'assemblea de la comuna entre els hereters, com ja hem vist, i que la seua funció era la de vigilar el compliment de les funcions del sequier pel que $\mathrm{fa}$ al manteniment de la séquia, però també aconsellar-lo en els judicis. D'ací que els veedors foren llauradors amb una acreditada experiència en l'exercici del reg, i amb cert prestigi social entre els seus veïns, semblants als hombres buenos de Múrcia.

Amb tot, és evident que aquesta capacitat judicial dels sequiers, majoritàriament llauradors, no agradava a tots els estaments socials. Per això, en les Corts de 1343 el braç militar es va queixar a Pere el Cerimoniós de la impossibilitat de recórrer les seues sentències, i encara van sol.licitar que se'ls pogués fer inquisicions anuals com es feia amb altres oficials reials, ja que tenien la capacitat de jutjar en nom del rei, però el braç reial s'hi va negar i tot va quedar en no res. ${ }^{44}$ En realitat, les sentències dels sequiers sí podien apel.lar-se davant del governador, d'acord amb un privilegi de Jaume II datat el 1300, segons el qual les decisions de tots els oficials de regne podien apel.lar-se davant del batle general (més tard anomenat governador) inclosos els sequiers (GLICK, 2003: 242), tot i que no devia ser allò més habitual. Amb tot, el que vertaderament preocupava els nobles en aquella ocasió, i en general, era la suposada poca capacitació dels sequiers com a jutges, i la denuncia d'imparcialitat per afavorir a sovint els seus familiars, amics i congèneres. Sens dubte, devia existir una certa confiança de la comuna o del consell municipal en la persona a qui delegava aquesta capacitat judicial i punitiva, ja que en aquest principi es basava l'èxit del sistema de gestió collectiva de la irrigació.

43 ARV, Governació, n. 2267, mà 11, f. 25r-30v; mà 88, f. 13; mà 6, f. 44.

44 Furs de València, citat per T. Gııck (2003: 238). A la Séquia Reial d'Alzira era al contrari, el governador no podia immiscir-se en les decisions del sequier reial. Sobre aquest tema vegeu Gıck (2003: 237-243). 


\subsection{Les característiques socials dels sequiers medievals i d'altres càrrecs}

En principi no existeix cap normativa que indique la necessitat o la prohibició de pertànyer a un estament social concret per exercir de sequier. ${ }^{45}$ Però és evident que la gran majoria dels que l'exerciren, almenys a partir del segle XIV, devien ser llauradors pels seus coneixements del funcionament del sistema i de la pràctica del regadiu. Per al segle XIII poden existir més dubtes al respecte, especialment en els sistemes de nova construcció, en els quals els primers sequiers potser necessitarien un major coneixement de caràcter tècnic per a organitzar el repartiment de l'aigua. Possiblement els sabaséquies del segle XIII no serien llauradors, ni tampoc els sobresequiers de Múrcia i Oriola, que serien una mena d'oficial municipal exercit per prohoms, i que tindrien més a veure amb la justícia que amb la gestió directa. Però no hi ha massa dubte que els sequiers baix-medievals i moderns valencians eren majoritàriament llauradors.

Per exemple, en un registre de l'arxiu de Governació de 1456 que recull diversa documentació relacionada amb el control reial de les comunes de València (només a nivell formal: permisos per a fer assemblees, jures de càrrecs, crides per a fer escures, etc.), de totes les persones esmentades (sequiers, lloctinents, guardes, veedors) en les que s'especifica la professió o condició social, tots són llauradors, excepte un sequier que és qualificat d'especier. ${ }^{46}$ De fet, per ara només s'ha pogut documentar el cas d'un sequier de l'Horta de València pertanyent a un altre estament, quan el 1437 fou elegit sequier de Rascanya el cavaller Jaume $\mathrm{Gil},{ }^{47} \mathrm{i}$ encara que degué ser un fet excepcional, caldria no descartar algun cas més esporàdic. Tanmateix, fora de les ciutats més grans de València i Oriola, i potser de Xàtiva, aquesta darrera situació seria impensable.

Una altra cosa diferent serien els llauradors especialitzats en l'exercici d'aquest càrrec, com una mena d'ofici que anaven exercint cada any en diferents séquies. Per exemple, sabem que el sequier de Mislata dels períodes 1404-05, 1407-10 i 1417 fou Bononat Prats, que en 1412 i 1417-19 ho va ser també de Favara, i alhora és el mateix personatge que va arrendar la

$45 \mathrm{Amb}$ tot, a les ordenances de Banàger i Faitanar de 1732 n'hi ha un capítol, que no podem datar però que per la seua redacció i emplaçament sembla del segle XVI, en el qual es prohibeix expressament a nobles, cavallers i ciutadans arrendar la séquia i fer de sequiers. Aquestes ordenances estan publicades al segon volum de la versió castellana del llibre de Jaubert de PAssà (1844).

46 ARV, Governació, n. 4321, mà 2.

47 ARV, Governació, n. 2260, mà 8, f. 16r-18v. Vegeu també Guck (2003: 162). 
séquia de Benàger i Faitanar com a sequier el 1421, com ja hem vist adés. $\mathrm{Hi}$ ha documentat algun altre cas, i sembla que aquests personatges podien arribar a fer societats per a compartir despeses durant l'exercici del càrrec $\mathrm{i}$ canviar-se a l'any següent, o també avalant-se mútuament amb la fermança davant del comú. Alguns, fins i tot, transmetien l'ofici de pares a fills. ${ }^{48} \mathrm{~A}$ més a més, pareix existir una certa mobilitat entre séquies, i alhora un possible repartiment zonal, ja que en l'exemple que hem vist totes són séquies de l'Horta Sud. És evident, doncs, que hi havia una clara especialització en l'ofici d'aquests sequiers-arrendadors, ${ }^{49}$ i que estem també al davant d'uns professionals que arrendaven les séquies amb una clara finalitat pecuniària. Per descomptat, no sempre s'ocuparien directament de l'exercici de les seues funcions, puix la delegarien en els lloctinents. ${ }^{50}$ Però no deixen de ser només uns pocs casos documentats, que podrien ser excepcionals en un context més ample, i especialment fora de l'Horta de València, per la qual cosa caldria fer una recerca de major entitat documental que encara està pendent. De fet, les ordenances més tardanes de les comunes de València, i la normativa municipal d'altres viles, tendeixen a prohibir exercir el càrrec de sequier més d'un any seguit, tot i que açò només implica la necessitat de moure's entre les diverses séquies com ja hem vist.

En qualsevol cas, sembla prou més probable que en la majoria dels casos allò més habitual fos l'arrendament d'una séquia i l'exercici del càrrec o ofici com una activitat esporàdica, malgrat que en alguns casos es pogués arribar a una certa especialització quan algú es convertia en sequier diverses vegades. En les comunes de València, com que la subhasta es feia a la mateixa assemblea general de la comuna, a la que només podien assistir els hereters, allò més habitual és que el sequier acabés sent un llaurador de la pròpia séquia, tot $i$ que no sempre necessàriament. A Favara, en concret, no podia ser sequier algú estrany a la séquia, és a dir que havia de

48 L'Antoni Prats que el 1441 era sequier de Benàger i Faitanar sembla fill, o almenys familiar, de Bononat Prats. ARV, Governació, n. 2267, mà 11, f.25r-30v.

49 Sobre aquest tema i les referències citades vegeu Martínez Sanmartín (en prensa) i Guick (1967). Per a l'arrendament de 1421 vegeu referència en la nota 26 . Cal dir que la coincidència d'alguns anys en diferents séquies és perquè les assemblees de les comunes en les que s'arrendava el càrrec es feien sempre per Pasqua, per tant l'exercici del càrrec començava i acabava entre març i abril.

50 En 1437 Joan Davó declarava que cinc anys abans mossén Jaume Gil fou elet sequier de Rascanya i immediatament el nomenà a ell lloctinent, que és qui feu escurar les séquies (vegeu nota 47). Amb tot, cal anar espai amb aquest exemple, puix el nomenament d'un cavaller com a sequier és tota una excepció. 
ser hereter. Tanmateix, com que una persona podia tenir propietats a més d'una séquia, la qual cosa era força habitual, un mateix llaurador podia ser sequier de més d'una séquia en anys diferents. ${ }^{51}$

En el cas dels municipis, sabem que a Gandia els llauradors com a molt accedien al segon escaló de l'administració municipal en el que es troba el sequier, i fins $\mathrm{i}$ tot en alguna ocasió es detecten sequiers que no són llauradors, com per exemple un fuster (APARISI, 2008). De Castelló tenim molt poques dades, però sembla que no era molt diferent. En el cas de Vila-real, que de nou és la localitat millor estudiada, Immaculada Román (2000: 110) ha pogut reunir una llarga nòmina de 144 sequiers de les tres séquies que hi havia, per a 83 anys entre finals del XIV i al llarg del XV, i ha pogut calcular que el $58 \%$ només foren sequiers una vegada, el $20 \%$ dues vegades, el $14^{\prime} 5 \%$ tres vegades, i la resta més de quatre, destacant el cas d'un sequier que ho fou dotze vegades. A més, era força habitual que els sequiers que repetien ho fessen sempre a la mateixa séquia. Finalment a Sueca, que com dèiem era una comunitat rural una mica més petita que les viles, al segle $\mathrm{XVI}$ els sequiers eren també sempre llauradors, i de vegades repetien; però sobretot, en aquest cas, el que sí es detecta és un acaparament dels oficis de sequier i sobresequier per part de les famílies més arrelades i amb major quantitat de terra (Furió, 1982: 26). En conclusió, doncs, cal pensar que l'interès $o$ no per exercir de sequier que tenien els diversos grups socials depenia de l'especialització econòmica local i de la complexitat social de la seua oligarquia.

És per això que, en principi, és lògic que la majoria dels sequiers foren llauradors, però el que no està tan clar és el seu nivell econòmic i social, que està per estudiar amb una especificitat suficient. Aquest càrrec no devia ser ocupat sempre necessàriament pels llauradors amb una major capacitat econòmica, perquè no donava grans beneficis, tot i que no hem de descartar-ho en ocasions perquè hem de pensar també en la qüestió del prestigi social dins de la comunitat rural. Depenent del lloc, doncs, sembla evident que a les comunes de València i a les viles reials la major part de les vegades devien ser llauradors mitjans, amb unes poques terres i una mínima disponibilitat econòmica per fer front als requeriments del càrrec. De fet, tant els Furs com les normatives comunals i municipals posen els bens del sequier com a fiança davant d'una mala actuació seua, per tant és evident que calia garantir una certa solvència. ${ }^{52}$ Així, a Favara es demanava que

51 Els capítols de Favara, de fet, prohibien els hereters de Rovella ser sequiers. També als que alguna vegada haguessen denunciat al comú en un plet. Referència en notes 28 i 29.

52 Un document de 1404 qualifica el sequier i els veedors de Favara com a "pagesos grossos". ARV, Governació, 2189, mà 1, f. 42r, citat per Guck (2003: 79). 
algú avalés el sequier amb 1000 florins i, si no acomplia les seues obligacions d'acord amb els capítols, li podien embargar els bens personals. A Mislata la fermança o aval demanat era de 100 lliures, que igualment es faria efectiva si no bastaven els bens expropiats al sequier infractor.

A l'Horta de València, de vegades, eren els senyors els que avalaven un vassall de confiança perquè fos sequier. $A$ més, en el cas dels sequiers professionalitzats s'avalaven mútuament entre ells en anys diferents. Per contra, a Vila-real es pot comprovar com els avals provenien normalment de la família, i només a vegades de sequiers d'altres anys. Però en cap cas es tractava dels prohoms que exercien càrrecs de primera fila com el de jurat - justícia, i en pocs casos arribaven a formar part del consell. Caldria fer estudis prosopografies dels sequiers coneguts en diferents llocs per arribar a conclusions més fefaents. De fet, és important diferenciar entre les diverses zones geogràfiques del país, puix no devia ser el mateix fer de sequier a I'horta de València que a l'horta d'una vila, i menys encara a l'horta d'un petit lloc de senyoria.

En qualsevol cas, aquest origen social dels sequiers, com a càrrec tècnic, contrasta clarament amb l'origen social dels dirigents de les comunes de València, que són els diputats. Aquests conformaven una junta de govern col.lectiva, que era equivalent al govern dels jurats als municipis. De fet, tant uns com els altres exercien el mateix paper, segons el model institucional comunal o municipal. En el cas de les comunes, doncs, els diputats solien ser cavallers - de vegades podien ser-ho els titulars dels llocs de senyoria per on passava la séquia, o els seus representants-, burgesos de València (notaris, mercaders, etc.), i en menor mesura eclesiàstics; en definitiva, tots terratinents. Els diputats de Favara que s'esmenten al capítol aprovat en l'assemblea de 1493 són tots tres cavallers, i en el cas de l'arrendament de Mislata de 1415, que actua també com a acta de l'assemblea, dels tres diputats triats pel comú, un pertany als Escrivà de Romaní (senyors de Patraix) $i$ un altre és tractat de micer, cosa que indica la seva prominència social, tot i que al document només se'ls identifica com habitadors de la ciutat de València. Els eclesiàstics, per contra, no eren tan habituals en aquest segle, excepte quan eren senyors, com el comanador de Torrent de l'Orde de l'Hospital en el cas de Benàger i Faitanar per posar un sol exemple. Per contra, en època moderna la seua presència a la junta directiva fou tan habitual com la de la resta d'estaments, segurament degut al gran augment de convents que es va produir en aquest període, i per tant de les terres que aquestes tenien en propietat, establertes o arrendades als llauradors.

Com podem veure, doncs, hi ha una clara divisió social entre els diversos càrrecs de les comunes. El sequier, i segurament els veedors, solien ser llauradors a causa dels coneixements tècnics i pràctics que requerien les seues 
funcions, tot i que amb una certa capacitat econòmica i de prestigi social. El síndic solia ser un notari, per la necessitat d'acomplir les pràctiques legals de representació que li eren encomanades, de la mateixa manera que ho eren els càrrecs que no s'esmenten quasi mai a la documentació, com ara el clavari i l'escrivà. Finalment, els diputats, que són poc esmentats als capítols i apareixen poc a la documentació perquè no tenien assignada cap funció directa en la gestió de la irrigació, eren en realitat els que acaparen el control de la comuna com a organització col.lectiva dels hereters. I aquests solien ser cavallers, burgesos 0 , de vegades, representants dels senyors feudals.

\section{El sequiers entre els segles XVII I XVIII: de l'ocàs a la desaparició}

Per al segle XVI, i especialment per al XVII i el XVIII, la informació conservada als arxius sobre la gestió de la irrigació a l'Horta de València és una mica més abundant que per al període medieval, per això serien necessaris estudis específics amb una major consulta de documentació de la que hem treballat per als apartats anteriors. Pel que fa a treballs d'altres autors, la zona millor estudiada per a aquest període és la vall del Vinalopó, gràcies als treballs de Tomás Pérez Medina (en premsa), però allà es conservava encara el model del sobresequier municipal i els sequiers subordinats, típic de la governació d'Oriola, de manera que no es poden fer comparacions amb la resta del País Valencià, que és la zona de la que ens hem ocupat en aquest article. Per a la nostra zona d'estudi cal destacar també els treballs de Tomàs Peris Albentosa (2014) sobre la irrigació i les institucions de govern collectives, però no s'ha ocupat mai directament dels sequiers. En qualsevol cas, centrant-nos en les seues funcions, és evident que a la major part del territori en els segles XVII-XVIII molt poc o res no va canviar respecte a la situació anterior.

Potser una font adequada per a la normativa d'aquests segles, i a més allunyada de l'Horta de València i de les grans viles, podrien ser les cartes pobles que els senyors feudals donaren als nous colons que poblaren els llocs abandonats pels moriscos després de l'expulsió del 1609. Amb tot, es tracta en quasi tots els casos de petits llocs amb regs de fonts, molts d'ells a la muntanya, i amb una població completament camperola. En tots els casos el sequier és esmentat simplement com un càrrec més del consell municipal, tot i que de segona fila com ja era habitual. La diferència és que en algun cas el sequier seria elegit pels jurats com a Benicàssim, o s'arrendaria com a Alcàsser. Mentre que en la major part dels casos el sequier seria elegit directament pel senyor, com a Valldigna, Quartell, Benaixeve, Xella, Terrateig, Barxeta i Sant Joan de l'Ėnova, per posar els casos més explícits, 
o bé, com a molt, seria elegit pel senyor entre una terna de veïns indicada abans pel consell, com a Manuel, Antella, Algar de Palància i la baronia de Rugat. ${ }^{53}$ En aquests darrers casos sembla que només s'està reproduint la situació prèvia a l'expulsió dels moriscos, que molts senyors intentaren mantenir amb els nous colons. Així doncs, en conseqüència, les cartes pobles no ens aclareixen molt sobre una possible evolució del sequier. Més bé al contrari, ens confirmen que la situació dels sequiers a les petites comunitats rurals no era exactament la mateixa que a les grans hortes, tot i que segueixen igualment les indicacions dels Furs de València. ${ }^{54} \mathrm{~A}$ més, ens demostren que existia una gran estabilitat en l'exercici de les funcions d'aquest càrrecs.

\subsection{Del sequier al síndic en les comunes de València: un canvi del XVII-XVIII}

Per ara només tenim un arrendament de la séquia de Rascanya el 1607, tot i que per a aquesta data tan primerenca de la centúria no hi ha cap diferència amb els altres arrendaments baix-medievals que hem vist a l'apartat anterior. En conseqüència, resulta difícil comparar la situació del sequier i de les seves funcions al segle XVII amb la dels segles anteriors. Si ens fixem en capítols i ordenances, de les vuit séquies que n'hi ha no en coneixem de cap que fossen aprovades al segle XVII, i ni tan sols sabem si se'n van fer, a excepció de les de Mislata de 1629 i les de Tormos de 1630, que apareixen esmentades en altres fonts però que no s'han conservat. ${ }^{55}$ Tanmateix, les ordenances que s'aprovaren al llarg del segle XVIII, i especialment les de Rovella de 1699 i les de Favara de 1701, que són anteriors al Decret de Nova Planta, donen certa informació sobre certs canvis produïts amb anterioritat que intentarem aprofitar.

53 Estan totes publicades en GuINOT i Ardit (en premsa).

54 A la carta pobla d'Algar del Palància es diu que "en respecte de adovar-se los clams e calònies, així de la aigua de les zéquies [...], se hajen de guardar y guarden los furs del present Reyne, y fer $y$ executar aquells y aquelles conforme als dits furs del Reyne, estils, pràctica $y$ costums del zequiers y horta de la ciutat de València, y lo mateix se ha de guardar en lo executar les penes de dites calònies". Nota anterior.

55 Les de Mislata s'esmenten en un document preparatori de les Ordenances de 1751, i les de Tormos les esmenta F. X. Borrull (1831: 39) perquè va veure a l'arxiu de la Reial Audiència el document que les aprovava. A Favara sabem que els capítols aprovats formalment pel governador el 1597 seguien en vigor el 1618, ja que l'escrivà de la séquia en va fer una còpia legal, la qual encara es conserva a l'arxiu de la comunitat de regants (Martínez Sanmartín i TEROL, en premsa), però no sabem si se'n van aprovar noves amb posterioritat en aquest segle; probablement no, perquè se'n van fer de noves el 1701. 
Als diversos capítols dels segles XV i XVI les funcions del sequier i del síndic estan molt ben definides i diferenciades: el sequier és qui s'encarrega del manteniment i de la gestió del sistema hidràulic, mentre el síndic té un paper de supervisió del sequier i de representació de la comuna de portes cap a enfora. A partir de finals del segle XVII i principis del XVIII, però, això va canviar. Tant les ordenances de Rovella com les de Favara atribueixen unes funcions molt similars al síndic i al sequier. És a dir, que el sequier segueix tenint encara unes funcions similars a les medievals que ja hem vist, i el síndic continua tenint un paper sobretot de supervisió del sequier, però les atribucions del síndic estan molt ampliades i té un major paper en la gestió del sistema. Així, tant el síndic com el sequier tenen ara encomanada la vigilància i manteniment de l'assut, especialment quan baixa fusta pel riu, moment en el qual han d'acudir tots dos, i junts han d'encarregar-se també de l'escura de la séquia (si no s'arrenda) i de recórrer-la setmanalment, així com també encarregar-se de les reparacions, quan això era abans una atribució exclusiva del sequier. A més, a l'edat mitjana l'arrendament és allò habitual i l'elecció d'un sequier l'excepció, però ara es deixa veure que l'elecció és més normal. En conseqüència, doncs, si a l'edat mitjana el sequier era un llaurador i el síndic un notari, ara s'introdueix la doble figura del síndic-llaurador i el síndic-notari, un pas necessari per les noves atribucions del síndic que un notari no tenia capacitat per a fer.

Podríem dir, doncs, que les funcions del sequier són més o menys les mateixes que abans, tot $\mathrm{i}$ que ara venen més especificades, mentre que el síndic-llaurador rep ara l'encàrrec d'estar molt més atent encara als afers del sequier i compartir-los amb ell personalment. En el cas de Favara una altra funció del sequier que ara que comparteixen tots dos és la d'acudir els dijous a la plaça de la Seu de València per jutjar, junts, els infractors, i tractar els afers relacionats amb la séquia, cosa que als capítols medievals també era una exclusivitat del sequier. Amb tot, cal dir que als de 1597 ja era així, de manera que el cavi venia gestant-se des de ben enrere. D'altra banda, l'equivalència d'ambdós càrrecs és ja tan evident el 1701, que es va introduir una clàusula o capítol nou perquè quan el síndic-llaurador fos del terme de València (els regants sobirans) el sequier fos dels llocs de senyoria (els jussans), i a la inversa en el següent bienni.

En el cas de Rovella no especifica qui ha de jutjar, però paradoxalment sí canvia la forma de repartir els diners de les multes i, així, si abans es repartien un terç per a l'acusador, un terç per al comú $\mathrm{i}$ un terç per al sequier, com era habitual a totes les comunes, i també a les viles amb un govern municipal del reg, a partir de 1699 el darrer terç és per al síndic de Rovella, i a més és l'encarregat de penyorar els que no paguen. Pel que fa a la séquia de Quart, amb unes ordenances aprovades definitivament 
el 1709 però començades a elaborar abans de la guerra de Successió, no esmenten ja per a res el sequier, i és el síndic qui s'encarrega de tot el que devia fer el sequier. Només especifica que s'arrendarà el cobrament del sequiatge i l'escura, però no la resta d'atribucions dels sequier medieval que ara les té el síndic.

A les ordenances aprovades després de la Nova Planta es continua esmentant el sequier, però ja no com a càrrec amb unes atribucions definides, amb l'única excepció de Benàger i Faitanar on la major part dels capítols són una còpia literal en castellà dels capítols medievals; però a partir del capítol 98 estan els que es van afegir el 1732, en els quals s'especifica que n'hi haurà un sequier i que si s'arrenda la séquia l'arrendador farà de sequier. Però les funcions de gestió són del síndic. En el mateix sentit, les ordenances de Mislata de 1751 també esmenten el sequier només com a sinònim d'arrendador del sequiatge, i no li atribueix cap funció especifica com sí que fa per al síndic. En el cas de Rascanya, que són ja de 1754, n'hi ha una situació bastant pareguda a les anteriors, puix existeix igualment un síndic i un sequier. El sequier apareix sempre com l'arrendador del sequiatge, si es fa així, però en aquest cas conserva algunes de les atribucions del sequier medieval, tot i que no per ocupar-se personalment de solucionar els problemes sinó per vigilant i avisar el síndic en detectar-los. En qualsevol cas, com arrendador del sequiatge (quan es fa així), és l'encarregat de pagar el sou a tots els altres oficials de la comuna, com ja era costum a l'edat mitjana. En les ordenances de Mestalla, aprovades el 1771, la situació és molt pareguda a la de Mislata i Rascanya. Els sequiers (perquè en són diversos, ja en el període medieval) s'esmenten com a sinònim de "arrendadores de la monda".

En conclusió, doncs, és evident la disminució, quan no desaparició, de quasi totes les funcions de l'antic sequier medieval, però en general el càrrec encara existeix. El síndic del XVIII, alhora, tampoc no té les mateixes funcions que el síndic medieval. En conseqüència, podríem dir, amb matisos, que el nou síndic-llaurador modern és l'hereu del sequier medieval, mentre que el nou síndic-notari modern és l'hereu de l'antic síndic medieval -que recordem que solia ser un notari-en el seu paper de representant de la comuna, assumint també ara les funcions de l'escrivà, i convertint-se així realment en un gestor administratiu. La desaparició del sequier, doncs, era inevitable per la dualitat de funcions amb el síndic-llaurador, i en un context de disminució de l'arrendament, fins a la seva completa desaparició en algun moment dels segles XVIII o XIX.

Tanmateix, la informació proporcionada per aquests fonts normatives no és suficient per esclarir per què s'ha produït aquest canvi, més enllà de constatar-lo. És evident que la clau està en el segle XVII, probablement en 
la seua segona meitat, tot $\mathrm{i}$ que possiblement ja comencés a gestar-se a finals del XVI. En els municipis, per contra, no hi ha indicis de canvi fins a la introducció de la legislació liberal i la formació de comunitats de regants de caire presidencialista (FERRI, 1997). Així doncs, tenint en compte els orígens del sequier, i sabent que no va sobreviure a l'abandonament del sistema de govern col.lectiu medieval i modern, podríem dir que aquest fou un càrrec tècnic de gestió de la irrigació propi d'una societat preindustrial.

\section{BiBLIOGRAFIA}

ApARISI, F. (2008): L'ascens d'unes elits rurals. L'horta de Gandia en la tardor medieval, Universitat de València, Treball de recerca per al DEA sense publicar.

BonNASSIE, P. (1991): From Slavery to Feudalism in South-Western Europe, Cambridge, Cambridge University Press.

BorRuLL, F. X. (1831): Tratado de la distribución de las aguas del río Turia, y del Tribunal de los Acequieros de la Huerta de Valencia, València, Imp. B. Monfort.

CAstillo, J. (1997): Els conflictes de l'aigua a la Safor medieval, Gandia, CEIC Alfons el Vell.

CHABÀs, R (1898): Distribución de las aguas en 1244 y donaciones del término de Gandía por D. Jaime I, València, Imp. F. Vives Mora.

CoRTÉs, J. (2001): Liber privilegiorum civitatis et regni Valencie. I. Jaume I, València, PUV.

FebreR, M. V. (1985-86): "Las ordenanzas medievales de la acequia de Mislata y los acequieros, vehedores y otros cargos ocupados en su gobierno", Annals de l'IDECO, pp 157-163.

FerRI Ramírez, M. (1997): "Reorganización de los regadíos valencianos en el siglo XIX: las ordenanzas liberales de la provincia de Valencia (18351850)", Áreas: Revista internacional de ciencias sociales, 17, pp 77-90.

FerrI Ramírez, M. i Sanchis lbor, C. (2001): "De comuners a regants: comunitat, territori i conflicte a les hortes valencianes", Afers: fulls de recerca $i$ pensament, 16-40, pp 641-654.

Furió, A. (1982): Camperols del País Valencià. Sueca, una comunitat rural a la tardor de l'edat mitjana, València, Institució Alfons el Magnànim.

GarCIA-Oliver, F. (1987): El Llibre d'Establiments de Gandia. Imatges i missatges en una vila medieval, Gandia, Ajuntament de Gandia.

Garcia Edo, V. (1994): Derechos históricos de los pueblos de la Plana a las aguas del río Mijares, Castelló de la Plana, Diputació de Castelló.

GIL VICENT, V. (2002): Ordenances municipals de Vila-real (segles XIV-XVIII), València, PUV. 
GLICK, T. F. (1967): "Dos documentos medievales referentes al Tribunal de las Aguas", BSCC, 43, pp 81-84.

Guck, T. F. (2003): Regadío y Sociedad en la Valencia medieval, València, Biblioteca Valenciana [edició ampliada i revisada respecte a la traducció de 1988].

Gregori, R. M., García Marsilla, J. V. i Pujades, J. (2008): Llibre de la Cort del justícia de València (1282-1287), València, PUV.

Gual Camarena, M. (1979): Estudio histórico-geográfico sobre la Acequia Real del Júcar, València, Institució Alfons el Magnànim.

GUICHARD (2001): Al-Andalus frente a la conquista cristiana. Los musulmanes de València, siglos XI-XIII, València, PUV.

GUINOT, E. (1991): Cartes de poblament medievals valencianes, València, Generalitat Valenciana.

GuINOT, E. (2007): "El gobierno del agua en las huertas medievales mediterráneas: los casos de Valencia y Murcia", en Espacios de poder y formas sociales en la edad Media, Salamanca, Universidad de Salamanca, pp 99-118.

GuINOT, E. i Ardit, M. (en premsa): Cartes de poblament valencianes modernes (1500-1800), València, PUV.

Guinot, E., Diéguez, M. A. i Ferragud, C. (2008): Llibre de la Cort del justícia de València (1280-1282), València, PUV.

Guinot, E. i Romero, J. (2007): "El Tribunal de les Aigües de l'Horta de València: continuïtat institucional i canvi social", en Derecho, historia y universidades. Estudios dedicados a Mariano Peset, vol. I, València, PUV, 2007, pp 755-769.

Guinot, E. i Selma, S. (2001): Las acequias de la Plana de Castelló, València, Generalitat Valenciana.

IbarRa Ruiz, P. (1914): Estudio acerca de la institución del riego en Elche, Madrid.

Jaubert de Passà, F. (1844): Canales de riego de Cataluña y reino de Valencia, València, Imp. B. Monfort.

Labarta, A., Barceló, C. i Veglison, J. (2012): València àrab en prosa i vers, València, PUV.

LAIRÓN, A. (2001): Libre de diverses estatuts e ordenacions fets per lo consell de la vila de Algezira, València, PUV.

López Elum, P. (2001): Los orígenes de los Fueros de Valencia y de las Cortes en el siglo XIII, València, Biblioteca Valenciana.

Martínez Sanmartín, L. P. (en premsa): "Experts, perits i tecnosistemes hidràulics. La séquia de Mislata i les comunitats de regants de l'horta de València", Recerques. 
Martínez Sanmartín, L. P. i Terol, V. (en premsa): "El libro de los actos, provisiones y reuniones de la acequia de Favara (1362-1521): aproximación a un registro clave para la historia del regadío en la Huerta medieval de Valencia", en Landscapes, Irrigation, Society. Homenaje a T. Glick.

Ortega, J. i Lallena, C. (2012): "Formas feudales de especulación agraria: viñas, villa y acequias en el sur de Aragón (ca. 1170-1240)"en Hidráulica agraria y Sociedad feudal. Práctica, técnicas, espacios, Valencia, PUV, pp 79-102.

Parra Villaescusa, M. (2013): "Control del agua y poder en la frontera sur valenciana: la huerta de Orihuela (siglo XV)", Roda da Fortuna. Revista Eletrônica sobre Antiguidade e Medievo, Vol. 2, n. 1-1, pp 470-500.

Pérez Medina, T. (en premsa): "El gobierno local del agua en las huertas del Vinalopó durante la época moderna", en Landscapes, Irrigation, Society. Homenaje a T. Glick.

Peris Albentosa, T. (2014): "El ejercicio de la autonomía local en las acequias de la Huerta de Valencia: la olvidada imbricación municipal (siglos XIII-XIX)", Documentos de Trabajo - SEHA, n. 1404, on line.

ROMÁN, I. (2000): El regadío de Vila-real durante los siglos XIII y XV. Origenes, administración y conflictos, Vila-real, Ajuntament de Vila-real.

SARASA, E. (1989): "La memoria del agua: La economía hidráulica en el Valle Medio del Ebro, zun ejemplo de supervivencia o de nueva implantación tras la conquista cristiana en el siglo XII?", Aragón en la Edad Media, 8, pp 633-646.

SaRASA, E. (2008): "La economía hidráulica en el Valle Medio del Ebro: de la explotación islámica a la cristiana", en Musulmanes y cristianos frente al agua en las ciudades medievales, Valladolid, Universidad de Valladolid, pp 155-172.

Sempere, F. i Garcia Edo, V. (2003): Privilegios y concesiones del término general del castillo de Nules en época foral (1251-1709),València, Ajuntament de Nules.

TEIRA, F. J. (1968): El régimen jurídico de aguas en el llano de Lérida, siglos XII al XVIII, Barcelona, Universitat de Barcelona.

TORRES Fontes J. (1975): El regadío Murciano en la primera mitad del siglo XIV, Múrcia, Junta de Hacendados de la Huerta de Murcia.

Verdú CANo, C. (2011): El palmeral de Elche. Un paisaje andalusí, Granada, Alhulia. 
